\title{
Article
}

\section{The OII Shale Transformation in the Presence of an Acidic BEA Zeolite under Microwave Irradiation}

Neto, Ana, Thomas, Sébastien, Bond, Gary, Thibault-Starzyk, Frédéric, Ribeiro, Filipa and Henriques, Carlos

Available at https://clok.uclan.ac.uk/13920/

Neto, Ana, Thomas, Sébastien, Bond, Gary orcid iconORCID: 0000-0001-53472341, Thibault-Starzyk, Frédéric, Ribeiro, Filipa and Henriques, Carlos (2014) The Oil Shale Transformation in the Presence of an Acidic BEA Zeolite under Microwave Irradiation. Energy \& Fuels, 28 (4). pp. 2365-2377. ISSN 0887-0624

It is advisable to refer to the publisher's version if you intend to cite from the work. http://dx.doi.org/10.1021/ef4023898

For more information about UCLan's research in this area go to http://www.uclan.ac.uk/researchgroups/ and search for <name of research Group>.

For information about Research generally at UCLan please go to http://www.uclan.ac.uk/research/

All outputs in CLoK are protected by Intellectual Property Rights law, including Copyright law. Copyright, IPR and Moral Rights for the works on this site are retained by the individual authors and/or other copyright owners. Terms and conditions for use of this material are defined in the policies page. 


\section{The oil shale transformation in the presence of an}

\section{acidic BEA zeolite under microwave irradiation}

3 Ana Neto ${ }^{\dagger,}$, Sébastien Thomas ${ }^{\ddagger}$, Gary Bond ${ }^{\S}$, Frédéric Thibault-Starzyk ${ }^{\ddagger}$, Filipa Ribeiro ${ }^{\dagger}$. Carlos

4 Henriques*,† $^{*}$

$5+$ IBB - Institute for Biotechnology and Bioengineering, CEBQ, Instituto Superior Técnico UTL, Av. Rovisco Pais, 1049-001 Lisbon, Portugal.

$7 \quad{ }^{\ddagger}$ Laboratoire Catalyse et Spectrochimie, ENSICAEN, Université de Caen-Basse Normandie, CNRS, 6 boulevard Maréchal Juin, 14050 Caen, France.

$\S$ School of Forensic and Investigative Sciences, University of Central Lancashire, PR1 2HE, United Kingdom.

\section{KEYWORDS}

12 Oil shale, Microwave heating, Zeolite BEA, Kerogen 


\section{Abstract}

2 The transformation of an oil shale sample from the Autun Basin in the Massif Central, France,

3 was studied using two different heating strategies: microwave irradiation and conventional

4 heating. Microwave heating was performed using a single mode cavity operating at a frequency

5 of $2.45 \mathrm{GHz}$, under inert atmosphere. Heating of the sample generated liquid products of similar

6 composition, either using microwave or conventional heating. The liquid products yield was

7 similar in both cases, while the overall energy requirements were much lower using microwave

8 irradiation. The influence of water vapour in the oil shale decomposition was also studied under

9 microwave energy. In order to simulate the oil shale organic fraction conversion in the presence

10 of an acidic zeolite catalyst, the oil shale sample was mixed with $5 \mathrm{wt} . \%$ BEA zeolite and heated

11 under microwave irradiation. It was found that the liquid products yield decreased, along with an

12 increase in the coke produced. Gaseous and liquid products recovered showed a tendency for the

13 production of lighter components when in the presence of zeolite. The aromatic character of the

14 oils was more important when using microwaves, especially in the presence of zeolite. 


\section{INTRODUCTION}

2 Global demand for crude oil has been increasing for several decades and it is expected to

3 continue to grow ${ }^{1}$. The depletion of light crude oil reserves has meant that the development of

4 alternative energy sources has become vital. Hence, the use of heavy oils and other heavy

5 feedstocks for liquid fuel production has been increasing. In fact, recent efforts in the petroleum

6 industry have been focused on improving the existent technology so that a larger fraction of the

7 oil recovered (the barrel "bottom" fraction) can be converted to higher valuable products ${ }^{2,} 3$.

8 Unconventional hydrocarbon resources, including heavy oil, oil sands and oil shale, also have

9 potential to provide a valuable source of liquid hydrocarbons, since they exist in significant

10 quantities. Conventional oil reserves worldwide are estimated at 1.0 trillion barrels with an

11 additional 1.7 trillion barrels of possible/undiscovered reserves ${ }^{4}$. Canadian oil sands reserves are

12 estimated at 1.7 trillion barrels, while oil shale known resources are estimated at 2.9 trillion

13 barrels, with 2.0 trillion barrels located in the USA ${ }^{4,5}$.

14 Oil shale is a fine-grained sedimentary rock containing relatively large amounts of organic

15 matter, kerogen. This is a carbonaceous material from which oil and combustible gas can be

16 extracted by destructive distillation ${ }^{6}$. Several studies have been carried out concerning the

17 characterization of different oil shale types and their potential for liquid hydrocarbon generation

$18{ }^{7-9}$. The most important techniques used for characterization of potential source rocks are Rock-

19 Eval pyrolysis ${ }^{10}$, vitrinite reflectance measurements, X-Ray diffraction, FTIR and thermal 20 analysis (DTA-TGA).

21 Regarding oil shale processing, there are two main approaches: mining with subsequent surface

22 retorting and the in situ retorting processes ${ }^{6}$. In order to overcome the limitations imposed by

23 mining and retorting of oil shale, namely the disposal of spent shale, water resource needs and 
1 land surface alteration during the mining process, energy companies and petroleum researchers

2 have been trying to develop new technologies for in situ oil shale transformation, differing

3 mainly in the heating strategies that have been applied. The methodology proposed by Shell,

4 known as In situ Conversion Process (ICP), appears in this context ${ }^{11-13}$, with several patents

5 filled over the years and successful field pilots conducted in Colorado ${ }^{11}$. This process consists of

6 a series of underground heaters installed in holes drilled into the oil shale deposit; the electrical

7 resistance heaters heat the surrounding shale deposit to temperatures in the range of $250-400^{\circ} \mathrm{C}$

8 12. It takes several years to convert the kerogen contained in the oil shale into lighter

9 hydrocarbons, which are then pumped to the surface using conventional methods. Drawbacks

10 inherent to this approach are high energy requirements, long time needed to obtain significant

11 amounts of oil, as well as environmental issues, mostly related to groundwater contaminations

12 due to global heating of the soil.

13 Microwaves and radio frequency energy have also been proposed as alternative heating

14 methods for recovery of oil and gas from oil shale and oil sands ${ }^{14-19}$. The application of

15 microwave energy for oil shale transformation has been documented since at least 1981, in the

16 patent by Dumbaugh et al. ${ }^{20}$, which refers to the retorting process of oil shale and tar sand using

17 microwave irradiation at $2450 \mathrm{MHz}$ to heat the samples to temperatures about $370-650^{\circ} \mathrm{C}$.

18 Balint et al. ${ }^{21}$ developed a method using microwave irradiation of the natural mineral in a

19 pressure vessel, using an expelling medium to extract the kerogen, such as gaseous or liquefied

20 carbon dioxide or other gaseous or vapour hydrocarbon solvents. Both processes refer to

21 experiments performed at the laboratory scale. Several methods and apparatuses have been

22 proposed for the in situ recovery of liquid hydrocarbons from oil shale ${ }^{22-25}$, involving volumetric,

23 selective, rapid and controlled heating ${ }^{26}$, sometimes in combination with critical fluids or carbon 
1 sequestration. This latter case refers to the technology developed by Raytheon and Critical Fluids

2 Technologies ${ }^{27}$ in 2007 and is based on earlier radio-frequency based technologies from

3 Raytheon ${ }^{28}$. The process involves injecting carbon dioxide as a super critical fluid and a catalyst

4 into the well; in situ radio-frequency energy is applied to heat the rock formation. The resulting

5 product stream obtained, requiring further processing, consists of $\mathrm{CO}_{2}, \mathrm{CH}_{4}$, oil, steam/water and

6 organic vapours.

$7 \quad$ When using electromagnetic heating, the energy is directly absorbed by the material subjected

8 to radiation, avoiding energy losses to the system environment, which improves heating rates and

9 reduces thermal gradients. Dielectric heating is caused by an increase of the kinetic energy of

10 dipolar components of molecules under the effect of an electromagnetic field. Polar molecules or

11 ions tend to couple and align themselves to be in phase with the field (dipole relaxation); since

12 the microwave field is alternating in time, the dipoles are constantly oscillating at the microwave

13 frequency, (300 MHz to $300 \mathrm{GHz}$ ); this oscillation increases the kinetic energy and collisions

14 between molecules, producing random motion and, consequently heat ${ }^{29,30}$. The extent to which a

15 material can be heated under microwave irradiation is dependent on its dielectric properties. The

16 complex relative permittivity, $\varepsilon_{r}$, describes the ability of a material to store electric energy and it

17 is characterized by the dielectric constant, $\varepsilon_{r}$ ', and the dielectric loss factor, $\varepsilon_{r}{ }^{\prime \prime}$ :

$$
\varepsilon_{r}=\varepsilon_{r}{ }^{\prime}+i \varepsilon_{r}{ }^{\prime \prime}
$$

18 The dielectric constant reflects the capability of a material to be polarized by an electric field,

19 while the dielectric loss factor is related to the amount of energy actually absorbed and 20 subsequently dissipated as heat. The ratio of the dielectric loss by the dielectric constant defines

21 the dielectric loss tangent, which measures the ability of a material to convert electromagnetic 22 energy into heat at a given frequency and temperature. 


$$
\tan \delta=\frac{\varepsilon^{\prime \prime}}{\varepsilon^{\prime}}
$$

1 Absorption of microwave radiation by a material depends not only on the frequency of the

2 electromagnetic waves and the material temperature, but also moisture content, physical state,

3 composition and dimensions of the irradiated material ${ }^{30,31}$. When applying microwaves to heat

4 oil shale, it is expected that oil and moisture content will have an important influence on its

5 dielectric properties. Moreover, heating of the oil shale will depend on the kerogen polarizability.

6 Given the polar nature of kerogen, dipole relaxation effects are improved and the material is

7 effectively heated. In fact, it was found that the loss factor would increase with increasing oil

8 shale richness at a frequency of $500 \mathrm{MHz}{ }^{29}$. The presence of heteroatoms, namely sulfur,

9 nitrogen and oxygen, also contribute to the increase of the polarization of this substance when

10 under the effect of electromagnetic radiation ${ }^{29}$. Finally, metals in the form of powders are good

11 microwave radiation absorbers ${ }^{15,16}$.

12 Water is known to absorb microwave energy very strongly, given its polar characteristics. In

13 many industrial microwave processes, the presence of water in the workload is essential for their

14 adequate operation ${ }^{30}$. Water present in the oil shale can therefore affect the electromagnetic

15 energy absorption ${ }^{32}$. Some studies report the variation of the dielectric properties of some oil

16 shale samples (Green River oil shale) with the variation in their water content. It was reported

17 that with increasing percentage of water saturation in the oil shale samples, both $\varepsilon^{\prime}$ and $\varepsilon^{\prime \prime}$

18 increased (frequency range of $1 \mathrm{MHz}$ to $1.8 \mathrm{GHz}$ ), therefore improving energy propagation and

19 absorption by the material ${ }^{33}$. A study to the dielectric properties of Jordanian oil shales ${ }^{34}$ also

20 showed that samples with higher moisture content presented higher loss factor values. 
1 The oil obtained from oil shale retorting often requires additional upgrading processes, when

2 compared to conventional crude oil ${ }^{35}$. Having this in mind, the present study tested the influence

3 of a zeolite, with acidic character, on oil shale transformation and resulting products recovered.

4 The goal was to try to obtain lighter products via direct contact of the oil obtained from kerogen

5 transformation with a catalyst under microwave irradiation which would possibly require less

6 processing for subsequent liquid fuels production.

7 The use of zeolite-based catalysts for cracking of high molecular weight compounds to lighter

8 and more valuable products is well known ${ }^{36}$. This type of catalysts has also been applied to shale

9 oil upgrading ${ }^{37,38}$. Williams et al. ${ }^{38}$ studied a two stage oil shale pyrolysis, where the reaction

10 products from kerogen decomposition flowed through a ZSM-5 catalyst bed at $400-550^{\circ} \mathrm{C}$ prior

11 to recovery. Pore dimensions of ZSM-5 zeolite prevent the formation of voluminous intermediary

12 compounds and consequently minimizes the formation of coke ${ }^{39}$. However, when the cracking of

13 large molecules is intended, a large pore structure is usually advantageous. For that reason, a

14 commercial BEA zeolite was used in this study.

15 The application of zeolite catalysts under microwave radiation has also been studied for various

16 reactions ${ }^{31,40}$. Dielectric heating of zeolites is possible and this phenomenon has been associated

17 to the migration of cations in the zeolite framework ${ }^{32}$.

18 In the present work, the transformation of an oil shale sample under microwave irradiation was

19 performed and the results obtained were compared to the transformation under conventional

20 heating. The influence of the presence of water vapour in the oil shale transformation under

21 microwave irradiation was evaluated. Moreover, the presence of a BEA zeolite together with the

22 oil shale was studied using microwave energy. Oil fractions obtained from decomposition of the 
1 oil shale in such conditions were characterized and compared with the results obtained under

2 conventional heating.

3 The purpose of this work resides on the feasibility study of the transformation of oil shale in

4 the presence of zeolite, under microwave radiation, and no scale-up was yet intended in this

5 context.

\section{MATERIAL AND Methods}

7 Experimental apparatus and operating conditions. Experimental studies using microwave

8 irradiation were conducted in a microwave system as represented in Figure 1. The microwave

9 system comprises a generator operating at a frequency of $2.45 \mathrm{GHz}$ with a maximum power

10 output of $1000 \mathrm{~W}$. From the generator, the microwaves pass through a water-cooled circulator,

11 which is used to prevent any reflected power from damaging the magnetron. This device only

12 allows microwaves to flow in one direction, towards the waveguide, while the reflected power is

13 diverted into a water-cooled load. The reflected power is measured using a probe at the inlet of

14 the water load. From the circulator, the microwaves then go through a standard rectangular brass

15 9A waveguide ( $86 \times 43 \mathrm{~mm}$ ), which can incorporate a variable coupling aperture, which consists

16 of a thin aluminium sheet with a rectangular orifice of variable dimension. The dimensions of the

17 coupling aperture affect the Q-factor of the cavity, which has the result of varying the E-field

18 density. For the experiments performed in the present study, the dimensions of the rectangular

19 orifice used were $31 \times 21 \mathrm{~mm}$.

20 The sample section of the waveguide has two vertical ports (47 mm diameter) where the reactor

21 is introduced and two smaller horizontal ports ( $17 \mathrm{~mm}$ diameter) to allow access to an IR

22 thermometer (OMEGA ${ }^{\circledR}$ ). To prevent microwave leakage, the ports length is over than twice 
1 their diameter. At the end of the waveguide a short circuit, or plunge tuner, is installed. The

2 plunge tuner is used to alter the internal length of the waveguide so that a standing wave is

3 generated. In this situation, it is possible to locate the position of maximum E-field in the center

4 of the sample section, where the reactor is placed. Maximum energy absorption means minimum

5 reflected power. Accordingly, tuning of the microwave cavity was performed by minimizing the

6 reflected power measured at the level of the water-cooled circulator.

7 The sample temperature, as measured by an infrared pyrometer, was used to control the power

8 supplied to the generator, by means of a PID control algorithm. The PID algorithm takes as input

9 the difference between the actual sample temperature (the IR thermometer measurement) and the

10 temperature set point and then acts on the forward power from the generator. Since the IR

11 thermometer measures the external surface temperature of the reactor wall, this temperature

12 reading had to be corrected to the actual sample temperature inside the reactor. This correction

13 was performed by introducing a thermocouple in the reactor after microwave heating. As the

14 system cooled down, both temperature readings (IR thermometer versus reading from the

15 thermocouple) were registered.

16 A quartz reactor was used to place the oil shale sample inside the microwave cavity, using $6 \mathrm{~g}$

17 of the sample (bed height of about $2 \mathrm{~cm}$ ). Helium was used as carrier gas with a flow rate of

$1820 \mathrm{~mL} / \mathrm{min}$.

19 The liquid products, obtained from oil shale decomposition, were recovered at the bottom of

20 the reactor using a cold trap $\left(-80^{\circ} \mathrm{C}\right)$. As the liquid products formed were quite viscous, they

21 were recovered from the reactor and from the collecting vessel via dilution in the minimal

22 amount possible of acetone. Pure samples were also recovered for elemental analysis of the oil. A 
1 gas collecting tube was placed after the cold trap. At the setup's outlet, the gas would flow

2 through a soap bubble flow meter for monitoring of the gas flow rate during reaction.

3 In order to study the oil shale transformation under microwave irradiation, the sample was

4 heated in a first step to $300^{\circ} \mathrm{C}$, where it was held for $10 \mathrm{~min}$, and then to $500^{\circ} \mathrm{C}$. The forward

5 power from the generator was altered to maintain a constant heating rate of $10^{\circ} \mathrm{C} / \mathrm{min}$. A

6 programmed temperature methodology was chosen so that the time of exposure at a given

7 temperature could be comparable with the conventional heating experiments.

8 To study the effect of water in the system under microwave irradiation, the carrier gas was

9 passed through a saturator filled with water at room temperature placed at the reactor entry, ca.

$10 \quad 2.5 \% \mathrm{H}_{2} \mathrm{O}$.

11 The presence of the zeolite was investigated using the mechanical mixture of $5 \mathrm{wt} . \%$ of zeolite

12 with the oil shale sample.

13 The same temperature program was used when testing the oil shale transformation in a

14 conventional oven. An electrical oven from Adamel - Lhomargy with automatic control,

15 Termolab, was used. Helium flow of $3 \mathrm{~mL} / \mathrm{min} / \mathrm{g}$ was also used to improve liquid flow through

16 the reactor into the oil recovery system. Products recovery was performed in the same way as for

17 microwave heating.

18 Materials Characterization. The oil shale sample used in this study was provided by Total

19 and originated from the "Assise de Millery" of the Autun Basin in the Massif Central, France.

20 The sample was crushed and sieved to a $40 \mu \mathrm{m}$ powder. The zeolite sample was a BEA zeolite

21 provided by Zeolyst (CP811 E-75) with global Si/Al ratio of 31.7.

22 Rock-Eval analysis was performed over the oil shale sample using $100 \mathrm{mg}$ of powder on a

23 Rock-Eval 6 apparatus. The sample was first maintained at $300^{\circ} \mathrm{C}$ where free hydrocarbons were 
1 volatilized and detected by FID (S1 peak is then obtained). Afterwards, the temperature was

2 progressively increased to release heavy hydrocarbons, along with the products from thermal

3 cracking of non-volatile organic matter in the rock (S2 peak). S2 indicates the rock's existing

4 potential to produce hydrocarbons. Finally, the residual carbon fraction, for Total Organic Carbon

5 (TOC) calculation, was determined by an oxidation step of the remaining sample at $850^{\circ} \mathrm{C}$.

6 The oils obtained were injected in a GC Shimadzu-9A, with a capillary column CP- Sil 5 CB

7 and equipped with a FID detector. The gas samples recovered in the gas collecting tube were

8 analyzed using GC-MS, for the experiments performed under microwave irradiation, and using

9 the GC Shimadzu-9A for the conventional heating experiments. The GC-MS used was a Trace

10 GC Ultra/DSQ II, with a Restek capillary column, RXi®-5 Sil MS. The GC-MS was also used

11 for characterization of the liquids obtained.

12 Simulated distillation was performed with the oil samples (after roto-evaporation of the

13 solvent) according to the ASTM method D7500. FTIR - ATR was used for analysis of the liquid

14 samples. The spectrometer (Nicolet Magna 750, provided with a MCT detector) was equipped

15 with an ATR accessory from Specac, with a single reflection diamond crystal. TGA analysis was

16 used to evaluate the amount of organic matter left in the spent shale recovered from the reactor

17 after each experiment. The thermo-gravimetric experiments were recorded on a Setaram TG-

18 DTA 92 instrument operating under nitrogen with a flow rate of $30 \mathrm{~mL} / \mathrm{min}$ through the furnace

19 in the following conditions: sample weight about $30 \mathrm{mg}$, heating from room temperature up to

$20900^{\circ} \mathrm{C}$ at $5^{\circ} \mathrm{C} / \mathrm{min}$. Afterwards, the sample was calcined at $1000^{\circ} \mathrm{C}$, under air flow at $30 \mathrm{~mL} / \mathrm{min}$.

21 Carbon, hydrogen, nitrogen and sulphur contents were determined for both the spent shale

22 samples and the oil sample obtained from oil shale decomposition under microwave irradiation. 


\section{RESUltS AND Discussion.}

2 The oil shale sample was first characterized using Rock-Eval pyrolysis ${ }^{41}$ to evaluate its

3 potential for hydrocarbons generation. The total oil potential of the sample, defined as the sum of

4 peaks $S 1$ and $S 2{ }^{41}$ was found to be $488.6 \mathrm{mg}$ of hydrocarbon per gram of rock ( 48.9 wt.\%). The

5 amount of residual carbon in the sample after pyrolysis is not significant, given that the Total

6 Organic Carbon (TOC) determined was of $49.8 \%$. $\mathrm{T}_{\max }$, where maximum release of hydrocarbons

7 takes place, also given by Rock-Eval analysis ${ }^{41}$, was $444{ }^{\circ} \mathrm{C}$, indicating an early mature stage of

8 the organic matter in the source rock ${ }^{42}$. $T_{\max }$ is indicative of the source rock maturation degree,

9 but it is also affected by the organic matter type, soil contaminations and the mineral matrix ${ }^{43}$.

10 For this reason, the $T_{\max }$ value found should be interpreted with caution. The application of this

11 parameter to oil shale samples is useful when comparing a series of rocks of different origins,

12 since higher $T_{\max }$ values indicate higher maturity of the organic matter ${ }^{44}$.

13 The Production Index, PI, defined in equation (3), can also be used for the evaluation of the

14 organic matter maturity. The $P I$ resulted in a value of 0.002 , since the value of the $S 1$ peak (0.93

$15 \mathrm{mg}$ hydrocarbons/g of rock) was much lower than the $S 2$ peak (487.71 mg hydrocarbons/g of

16 rock), indicating the presence of immature organic matter ${ }^{42}$.

$$
P I=\frac{S_{1}}{S_{1}+S_{2}}
$$

17 The quality or type of the organic matter can be described by the Hydrogen Index, HI, 18 commonly used for kerogen classification, as described by Peters and Cassa ${ }^{42}$. Hydrogen index

19 is defined as the amount of hydrocarbons generated by kerogen cracking (S2 peak) referred to the

20 TOC. This parameter is proportional to the amount of hydrogen present in the kerogen and it is,

21 for that reason, a measure of the rock's potential to generate oil. The hydrogen index obtained 
1 was $979 \mathrm{mg} \mathrm{HC} / \mathrm{g}$ TOC. The kerogen present in the oil shale sample is thus of type $\mathrm{I}^{42}$ and it

2 shows great potential for oil production.

3 Oil shale transformation under microwave irradiation. Heating of the oil shale sample

4 under microwave irradiation resulted in the formation of a liquid product flowing down from the

5 oil shale bed, along with intense vapour formation. Vapours were then condensed in cold traps.

6 Samples from the gas product were recovered in a gas collecting tube and were subsequently

7 analyzed by GC-MS. After the oil shale transformation, the solid residue (spent shale) was

8 retrieved from the reactor for posterior analysis.

9 Data recorded from the PID control of the power supplied to the microwave generator was 10 useful to estimate the actual temperature where the oil shale transformation took place. As shown

11 in Figure 2, the power level behaviour is rather constant during heating of an oil shale sample,

12 until the power output suffers a sudden increase, corresponding, in this case, to a temperature of

$13300^{\circ} \mathrm{C}$. This temperature is assigned to the decomposition temperature of the oil shale. The rapid

14 variation in the power level is believed to be related to the change in the loss factor (dielectric

15 loss tangent) of the sample, which may be affected by changes at the molecular or structural

16 levels of the material, such as its decomposition ${ }^{45}$.

17 Considering the result from Rock-Eval analysis, where $\mathrm{T}_{\max }$ was observed at $444^{\circ} \mathrm{C}$, it is

18 interesting to note the difference in the transformation temperature between both heating

19 methods. In fact, the temperature reading during microwave irradiation using the infrared

20 temperature probe is taken as an average of the sample's bed temperature. Hot spots caused by

21 increased local absorption of radiation could promote oil shale transformation, while the mean

22 temperature of the bed is lower than the one observed during conventional heating. Hot spot

23 formation in gas/solid heterogeneous catalytic systems, as well as selective heating of certain 
1 active centres, has been suggested in the literature ${ }^{31,46-48}$. In the case of an oil shale sample,

2 selective heating would occur due to the presence of metal particles, which can be heated to high

3 temperatures under microwave irradiation ${ }^{31}$ originating a local temperature increase within the oil

4 shale bed.

5 Additionally, as the sample is heated under microwave irradiation, the oil trapped in the solid

6 becomes liquid, interacting more strongly with the microwave field, the result of which is to force

7 the layered structure of the oil shale apart, allowing the oil to be released at lower temperature.

8 On the other hand, important temperature gradients from the bulk to the reactor walls could

9 also be present during microwave heating. Since the reactor walls are in contact with ambient air,

10 the sample's temperature is lower closer to these points, decreasing the average oil shale

11 temperature observed. Calibration of the temperature reading by the IR thermometer during

12 microwave heating was performed so that the average temperature of the sample would be close

13 the desired temperature, for comparison with conventional thermal heating experiments. The

14 maximum temperature difference observed between the reactor walls and the bulk of the sample

15 was of $87^{\circ} \mathrm{C}$.

16

17 Oil shale transformation under conventional heating. In order to assess the microwave

18 heating system for oil shale conversion, the sample was also tested under conventional heating

19 using an electrical furnace and the same flow rate conditions previously used.

20 A thermocouple was employed for temperature monitoring in the oil shale bed. In this case, the

21 identification of the transformation temperature was based on the gas flow rate monitoring at the

22 setup outlet. Figure 3 shows the gas flow rate variation during heating of the oil shale, as well as 
1 the temperature reading during the experiment. The point where the gas flow rate started to

2 increase was considered as the transformation temperature.

3 When heating the oil shale sample under these conditions the transformation was observed

4 around $380^{\circ} \mathrm{C}$. The temperature for maximum gas flow rate was observed in the range $442-$

$5 \quad 445^{\circ} \mathrm{C}$, which is in complete agreement with Rock-Eval analysis, where maximum hydrocarbons

6 release was detected at $444^{\circ} \mathrm{C}$.

7 Simulated distillation of the oil samples obtained under conventional and microwave heating

8 show very similar results. The variation in product distribution is almost negligible between both 9 samples.

10 The elemental weight composition of the oil obtained from oil shale transformation under

11 microwave heating is presented in Table 1, as well as the usual proportions of these elements

12 found in conventional petroleum ${ }^{6}$. The composition of the liquid fraction obtained from the oil

13 shale decomposition is within the same limits found for conventional petroleum. The hydrogen-

14 to-carbon molar ratio obtained was of 1.4, which is close to the lower limit for this parameter. A

15 higher hydrogen-to-carbon ratio is normally desired for use as a refinery feedstock. However, it is

16 known that unconventional hydrocarbon sources are not as advantageous as conventional crude

17 oil for the same purpose. Hydrogen-to-carbon ratios of 1.5 are typical for oil sands bitumen, but a

18 ratio as low as 1.3 has been found for U.S. tar sands ${ }^{6}$.

19 Thermo-gravimetric analysis of fresh and spent shale samples allowed the estimation of the

20 remaining organic material in the treated samples. Oil shale pyrolysis using thermogravimetric

21 analysis has been previously investigated ${ }^{9,49,50}$. It was found that, depending on the oil shale

22 type, its decomposition exhibits either single or a two-stage evolution of hydrocarbon material, in 
1 the temperature range of $250-620^{\circ} \mathrm{C}$. At temperatures higher than $600^{\circ} \mathrm{C}$, thermal decomposition

2 of carbonates takes place, due to the presence of minerals, such as calcite or dolomite.

3 Thermal treatment of fresh oil shale under nitrogen flow showed a two-stage decomposition

4 process (Figure $4 \mathrm{~A}$ and $\mathrm{B}$ ) where the transformation step at $720^{\circ} \mathrm{C}$ is most likely due to

5 carbonates decomposition ${ }^{49}$. Afterwards, an oxidation step allowed the combustion of residual

6 carbon from refractory material, such as heavy oils, tar-mats, coke ${ }^{10}$. The organic content was

7 then estimated summing the weight loss due to the first decomposition step, at temperature below

$8600^{\circ} \mathrm{C}$, and the residual carbon from the oxidation phase. For the fresh oil shale sample, the

9 organic content obtained was of $47 \%$, while the total organic content given by Rock-Eval 10 analysis was of $50 \%$.

11 Accordingly, TGA under nitrogen flow performed with the spent shale after microwave or

12 conventional heating showed different remaining organic contents, as shown in Figure 4. Total

13 weight loss due to organic carbon after microwave heating was of $23 \%$, as opposed to $14 \%$ for

14 the sample treated under conventional heating. Also, Figure 4 shows different thermal

15 behaviours regarding said samples. Both fresh oil shale and spent shale from microwave heating

16 present two decomposition steps, at $450-460^{\circ} \mathrm{C}$ and $720^{\circ} \mathrm{C}$ (Figure 4B). On the other hand,

17 spent shale from conventional heating only presents the step at higher temperature (Figure 4A),

18 meaning that it mainly contains the heavier products fraction. This result suggests that the spent

19 shale from microwave heating contains a higher amount of organic matter yet to be recovered, as

20 opposed to the spent shale from conventional heating. This observation is consistent with the

21 average lower temperature of the oil shale bed during microwave irradiation, due to lack of

22 reactor insulation, suggesting that part of the sample did not reach the optimum temperature to

23 promote kerogen transformation. 
1 Elemental analysis of the solids obtained after oil shale decomposition (Table 2) also shows

2 lower carbon content in the spent shale when using conventional heating than when microwaves

3 were applied, which is in agreement with the TGA results.

4 The oil obtained after microwave irradiation of the oil shale has a hydrogen-to-carbon ratio

$5(\mathrm{H} / \mathrm{C})$ of 1.4 , as previously referred, while fresh oil shale presents a ratio of 1.3. A good

6 correspondence between both values was expected, since the organic matter that constitutes the

7 oil recovered is originated from kerogen decomposition present in the fresh oil shale.

8 The recovered spent shale samples, in general, present a lower hydrogen-to-carbon ratio, when

9 compared to fresh oil shale, mainly due to the decrease in the total carbon content of the spent

10 shale.

11 Zeolite influence in oil shale transformation. Mixing a zeolite with the oil shale sample

12 under microwave heating caused a decrease in the transformation temperature, which was

13 observed at $245^{\circ} \mathrm{C}$, as shown in Table 3 . The temperature reading was recorded as previously

14 described and the sample's decomposition was observed at lower temperature than the one of

15 pure oil shale transformation under microwave irradiation (Figure 5). A sudden increase in

16 power during heating of the sample mixed with zeolite is also observed in Figure 5, indicating

17 the moment where transformation of the oil shale takes place. This process is endothermic and, as

18 the sample heats, it can cool easily. However, as the oil is released from the sample, its organic

19 content decreases and higher power is needed to maintain the temperature. The result is the

20 appearance that two powers are applied for one temperature.

21 When conventional heating was used, the observed transformation temperature was basically

22 the same for both cases studied. 
1 Table 3 also presents the mass balance relating to the initial organic content, using as

2 calculation basis the amount of organic material determined with TGA in the initial sample, $m_{i}$.

3 The calculation basis was chosen assuming that the mineral matrix of the oil shale stays constant

4 during heating of the sample.

5 The liquid products yield, $Y_{\text {liquid, }}$ was determined using the amount of liquid recovered in the

6 condenser and the initial amount of organic matter in the oil shale sample.

$$
Y_{\text {liquid }}=\frac{m_{\text {liquid }}}{m_{i}} \times 100
$$

7 The amount of organics not recovered in the liquid or gas fractions, $m$ not recovered, was 8 determined using the data from TGA of the spent shale.

$$
m_{\text {not recovered }}=O M_{\text {spent }} \times m_{\text {spent }}
$$

9 where $O M_{\text {spent }}$ refers to the organic material in the spent shale determined by TGA and $m_{\text {spent }}$ is

10 the weight of spent shale recovered from the reactor. This parameter was then related to the initial

11 amount of organic material in the sample.

12 The amount of organic material in the gas produced was calculated considering that

$$
m_{i}=m_{\text {liquid }}+m_{\text {not recovered }}+m_{\text {gas }}
$$

13 The gas products yield was then defined as

$$
Y_{\text {gas }}=\frac{m_{\text {gas }}}{m_{i}} \times 100
$$

14 The conversion of the oil shale was used to evaluate the degree of transformation of the organic

15 material under microwaves or conventional heating.

$$
\text { Conversion }=\frac{m_{\text {products }}}{m_{i}}
$$

16 where

$$
m_{\text {products }}=m_{\text {liquid }}+m_{\text {coke }}+m_{\text {gas }}
$$


1 The organic material present in the spent shale is due (i) to the presence of non-transformed

2 kerogen - evidenced by the first weight loss in the TGA weight profile for the spent shale from

3 microwave heating (Figure 4), and (ii) to the presence of heavier compounds that remain in the

4 solid, after decomposition. These compounds came from the transformation of the organic

5 material and thus were considered as coke, $m_{\text {coke }}$.

6 The amount of coke produced was calculated from the increment observed in the weight loss

7 upon TG analysis during the oxidation step of the spent shale. In fact, the weight loss during

8 TGA using air flow is due to a heavier products fraction, given that it was not decomposed under

9 nitrogen flow. Since this fraction of heavier products is also present in fresh oil shale, the amount

10 of coke produced during oil shale decomposition was estimated using the increment in the weight

11 loss observed under air flow:

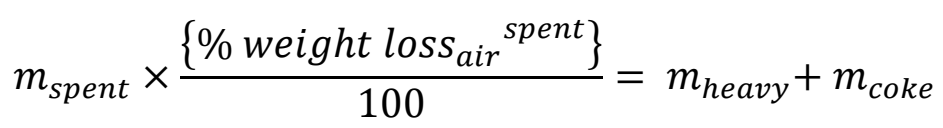

12 Where $m_{\text {heavy }}$ refers to the heavier products weight in the initial oil shale sample.

$$
m_{\text {heavy }}=m_{\text {oil shale }}^{\text {fresh }} \times \frac{\left\{\% \text { weight } \text { loss }_{\text {air }}^{\text {fresh }}\right\}}{100}
$$

13 Table 3 shows that liquid products yields resulting from microwave and conventional heating

14 were similar. However, as previously seen, the amount of organic matter in the spent shale after

15 conventional heating was lower, meaning that the amount of gas formed increased in this case.

16 When adding the zeolite to the oil shale under microwave irradiation, liquid products yield

17 decreased significantly. Nevertheless, total conversion of the oil shale under microwave heating

18 was about $70 \%$ of the initial organic content, with and without zeolite (Table 4). Total

19 conversion considers the total weight of liquid and gas formed, as well as the products adsorbed

20 in the spent shale (coke). The addition of zeolite caused an increase of the organics remaining in 
1 the spent shale, evidencing the increase in coke production, probably due to hydrocarbon

2 oligomerization reactions promoted in the acid sites of the zeolite. Williams et al. ${ }^{38}$ also used a

3 zeolite-based catalyst for the two stage pyrolysis of oil shale and obtained a similar result, with an

4 increased gas yield, while decreasing oil production, due to coke formation in the catalyst.

5 Under conventional heating, total oil shale conversion was also similar for both experiments,

6 with and without zeolite, while coke production was fairly the same in both cases (Figure 6).

7 Figure 6 shows higher organic content in the spent shale obtained after microwave heating, when

8 compared to conventional heating. This result could be associated to the lower temperatures

9 observed in the oil shale bed when using microwave irradiation, and is not necessarily related to

10 an increased coke production in these conditions. When heating the oil shale sample to promote

11 hydrocarbons release from the mineral matrix, cracking of the resulting compounds can also take

12 place at sufficient high temperatures ${ }^{14}$. When microwave heating was used, part of the sample

13 was at lower temperatures than when using conventional heating, which resulted in lower

14 tendency for cracking, leading to adsorption of heavier compounds in the spent shale.

15 Liquid products were analyzed, in the first instance, via gas chromatography, using a flame

16 ionization detector. Several reference compounds were used to divide the chromatogram in

17 different intervals of retention time (retention windows), which were then correlated with the

18 amount of sample eluted from the column within each retention window. The weight composition

19 determined this way was then related to the amount of liquid and gas products obtained, resulting

20 in the products yield shown in Figure 7.

21 The selectivity towards liquid products was defined as

$$
S_{\text {liquids }}=\frac{m_{\text {liquids }}}{m_{\text {products }}} \times 100
$$

22 While the selectivity towards gas products, 


$$
S_{\text {gas }}=\frac{m_{\text {gas }}}{m_{\text {products }}} \times 100
$$

1 For the light products fraction, “ $<\mathrm{C}_{6}$ ” the selectivity is given by

$$
S_{<C 6}=\frac{m_{\text {gas }}+w_{<C 6} m_{\text {liquids }}}{m_{\text {products }}} \times 100=S_{\text {gas }}+w_{<C 6} S_{\text {liquids }}
$$

2 And for the remaining product fractions:

$$
S_{i}=w_{i} S_{\text {liquids }}
$$

3 The amount of gas produced was considered in the " $<\mathrm{C}_{6}$ " product fraction. As noted before,

4 the overall products yield decreased when adding the zeolite to the system under microwave

5 heating. On the other hand, the global product yield was practically unaffected by the presence of

6 zeolite under conventional heating. When looking at each product fraction, light products yield

7 (“< $\mathrm{C}_{6}$ ” fraction) increased in the presence of zeolite under microwave irradiation (Figure 7A)

8 mainly because the selectivity towards gas products increased (Table 4). In fact, it was rather

9 expected that the amount of gas produced, related to the total amount of oil shale transformed,

10 would increase in the presence of zeolite due to an intrinsic catalytic cracking activity associated

11 with its acidic character. Figure $7 \mathrm{~B}$ shows that the " $<\mathrm{C}_{6}$ " and " $\mathrm{C}_{6}-\mathrm{C}_{10}$ " products yield

12 increased in the presence of the zeolite. This fact can also be related to the zeolite catalytic 13 activity.

14 A gas sample was collected when the gas flow rate measured at the setup outlet started to

15 increase. The gas was then analyzed using GC-MS, which allowed the identification of the main

16 compounds present in the gas. It was found that the major contributions were from ethane,

17 propane and propylene (fraction designated as $\mathrm{C}_{2} \& \mathrm{C}_{3}$ ), followed by butane and 2-butene.

18 Pentane and 1-pentene were also identified, and finally, to a lesser extent, hexane and 1-hexene.

19 This analysis was used as a qualitative approach for gas characterization (Figure 8A). 
1 For the conventional heating experiments, the gas recovered was analyzed using only gas

2 chromatography. In this case, methane was identified in the gas products, as well as the

3 compounds previously described in Figure 8B.

4 Water vapour influence, under microwave irradiation. The oil shale transformation was

5 also tested using microwave heating with Helium flow saturated in water vapour. The sample's

6 decomposition was observed around $242^{\circ} \mathrm{C}$, similar to what was observed when zeolite was used

7 (Figure 5). Since water is a polar molecule, it heats very easily when under the influence of an

8 electromagnetic field ${ }^{31}$. When water vapour is inside the microwave cavity along with the oil

9 shale sample, it helps heating the material and hence the proper conditions for the oil shale

10 decomposition are more easily achieved. The water vapour in the system, either from the

11 saturator or from desorption from the zeolite, can be adsorbed by the structure of the oil shale.

12 When interacting with the microwave field, steam is formed between the layers of this structure,

13 forcing them apart and releasing the oil at a lower temperature than the one observed when no

14 water vapour or zeolite were used.

15 In the presence of water vapour and heating under microwave irradiation, the liquid products

16 yield decreased (Table 3). Table 2 shows that the total carbon content did not decrease as much

17 as when only oil shale was used, which implies lower organic matter recovery. Consequently,

18 total oil shale conversion decreased, which was found to be around 49\% (Table 4).

19 ATR-FTIR of the oil samples. Attenuated Total Reflectance (ATR) is a widely adopted, non-

20 destructive, technique for the determination of chemical composition of materials based on their

21 chemical bonding. ATR analysis of the liquid samples from oil shale decomposition was used in

22 this work as a first approach to the oils characterization. 
1 In all samples analyzed, the normal $v(\mathrm{C}-\mathrm{H})$ stretching vibration bands are present,

2 corresponding to methyl and methylene bridge groups present in hydrocarbon chains. These

3 bands appear in the $2840-3000 \mathrm{~cm}^{-1}$ region ${ }^{51}$ (Table 5). Bending vibrations for methyl groups

4 appear at lower frequencies compared to their corresponding stretching vibrations. For the

5 symmetric vibration mode the band appears at $1375 \mathrm{~cm}^{-1}$, and at $1450 \mathrm{~cm}^{-1}$ for the asymmetric

6 mode ${ }^{51}$. For the $-\mathrm{CH}_{2}-$ group, there are four possible vibration modes: scissoring, rocking,

7 wagging and twisting. Scissoring vibration appears normally at $1465 \mathrm{~cm}^{-1}$, while the rocking

8 vibration mode appears at $720 \mathrm{~cm}^{-1}$, which was not possible to identify in the spectra obtained

9 (Figure 10). The other two vibration modes are normally less intense ${ }^{51,52}$. Table 5 presents the

10 bands identified in the spectra corresponding to $\mathrm{CH}_{3}$ and $\mathrm{CH}_{2}$ groups present in hydrocarbon

11 compounds in the shale oils.

12 Figure 9 and Figure 10 show the IR spectra for the shale oils obtained using microwaves and

13 conventional heating, with and without zeolite. The band at $2730 \mathrm{~cm}^{-1}$ may correspond to the $\mathrm{C}-$

$14 \mathrm{H}$ stretching vibration of groups $\mathrm{H}-\mathrm{C}=\mathrm{O}$, characteristic of aldehydes (these groups would appear

15 between $2650-2800 \mathrm{~cm}^{-153}$ ).

16 It is generally accepted that for wavenumbers greater than $3000 \mathrm{~cm}^{-1}$ the vibrations are due to

17 stretching of the $\mathrm{C}-\mathrm{H}$ bond of an ethylene or aromatic groups ${ }^{51}$. It is possible to distinguish the

18 presence of unsaturated compounds, shoulder around $3050 \mathrm{~cm}^{-1}$, in all samples, corresponding to

19 the $v\left(\mathrm{Csp}^{2}-\mathrm{H}\right)$ vibration ${ }^{54}$. Aromatic compounds are also present, as verified by the $3004 \mathrm{~cm}^{-1}$

20 band for the $v\left(\mathrm{C}_{\text {aromatic }}-\mathrm{H}\right)$ vibration and at $1603 \mathrm{~cm}^{-1}$ for the $\delta(\mathrm{C}=\mathrm{C})$ vibration of the aromatic

21 ring ${ }^{54}$. The bands at $1709 \mathrm{~cm}^{-1}$, corresponding to the $\mathrm{C}=\mathrm{O}$ stretching vibration ${ }^{51}, 1220 \mathrm{~cm}^{-1}, \mathrm{C}-$

22 O stretching vibration ${ }^{55}$ and $1360 \mathrm{~cm}^{-1}$ corresponding to the $\mathrm{CH}_{3}$ group bending vibration in

23 ketones ${ }^{51}$, are all due to the solvent ${ }^{56}$. 
1 The results are inconclusive about the presence of sulphur or nitrogen compounds in the oil

2 samples. For example, thiophene ring stretching would result in a band at $1350-1550 \mathrm{~cm}^{-1}$ and

$3 \mathrm{~S}=\mathrm{O}$ stretching vibrations would appear at $1030-1070 \mathrm{~cm}^{-1}{ }^{57}$. In the regions referred, there are

4 many contributions, making the assignment of the bands to a given compound or group very

5 difficult.

6 ATR analysis was used only as a qualitative approach to the oils characterization. No

7 conclusions were taken regarding which one of the samples would present heavier or lighter

8 compounds.

9 Simulated distillation. The liquid samples obtained from oil shale decomposition under

10 microwave and conventional heating were analyzed according to the ASTM method described

11 above. Prior to analysis, the solvent was evaporated. The oil samples analyzed contain a mixture

12 of hydrocarbons with carbon number lower than 110, corresponding to an atmospheric equivalent

13 boiling point (AEBP) of $735^{\circ} \mathrm{C}$, as described in API Research Project $44{ }^{58,59}$. The AEBP of 704

$14-712^{\circ} \mathrm{C}$ corresponds to n-alkanes with carbon number between 92 and 96.

15 Figure 11 shows the result derived from simulated distillation data of the oils obtained under

16 microwave irradiation. The curves represent the weight fraction recovered for each boiling point,

17 while the bar graph represents the result of the division of both curves into intervals related to the

18 number of carbon atoms found in conventional hydrocarbon mixtures ${ }^{60}$. The separation into

19 ranges was defined as follows:

$20 \quad$ Naphtha: $\quad<175^{\circ} \mathrm{C}$

$21 \quad$ Kerosene: $175-343^{\circ} \mathrm{C}$

$22 \quad$ Gas oil: $\quad 343-525^{\circ} \mathrm{C}$

$23 \quad$ Vacuum residue: $\quad 525-800^{\circ} \mathrm{C}$ 
$1 \quad$ Coke: $\quad>800^{\circ} \mathrm{C}$

2 The liquid sample obtained under microwave irradiation in the presence of BEA zeolite shows

3 very similar characteristics with the sample obtained in the absence of zeolite, as shown in Figure

4 11A. The naphtha fraction (Figure 11B) decreased when the zeolite was used, while the kerosene

5 fraction increased. For boiling points lower than $200^{\circ} \mathrm{C}$, the curve in Figure $11 \mathrm{~A}$ referring to the

6 oil obtained adding zeolite is not well defined, which increases the uncertainty in this result. On

7 the other hand, it would be expected a higher amount of light compounds in the oil obtained with

8 zeolite, due to the cracking activity associated with its acidic character, which was previously

9 observed for the kerosene fraction.

10 When water vapour was used during oil shale decomposition, the differences between the

11 simulated distillation curves (Figure $11 \mathrm{~A}$ ) were around $20^{\circ} \mathrm{C}$. Compared to the previous samples,

12 the residue boiling fraction (Figure 11B) increased, which indicates that the presence of high

13 boiling point products is more significant in this oil sample.

14 GC-MS analysis. GC-MS application for the characterization of petroleum-like products has

15 been known for many years. The application of both GC and GC-MS techniques was used for the

16 characterization of heavy residual oils of different sources ${ }^{61}$. Quantification of normal paraffins

17 and isoprenoids was used to evaluate if various pairs of oils were from a common source or not.

18 Shale oil has also been analyzed using GC-MS for the evaluation of the presence of biological

19 markers, such as isoprenoids, steranes and terpanes, in extracted and pyrolyzed oils ${ }^{62,63}$. This

20 type of description is important when referring to the overall structure characterization and origin

21 of the kerogen. In the present study, GC-MS was used for identification of the classes of

22 compounds present in the oils obtained from oil shale decomposition using different heating

23 methods, as described above. 
1 Data treatment for GC-MS analysis was performed using Thermo Scientific Xcalibur ${ }^{\circledR}$

2 software. The spectrum associated to each peak in the chromatogram was compared to the NIST

3 Standard Reference Database mass spectral library (NIST05) and a probable identification for the

4 components was found.

5 In order to better distinguish the liquids obtained under microwave irradiation, the several

6 compounds found with GC-MS where divided into classes, according to functional groups. Their

7 respective areas in the chromatogram were then compared (Figure 12), since the response

8 observed in the mass spectrometer for a given compound is proportional to its concentration in

9 the gas stream. In the presence of zeolite, it was observed a significant change in the aromatic

10 character of the liquid sample: the contribution from aromatics and polycyclic aromatic

11 hydrocarbons increased, while the alkane fraction was not changed. When water vapour was used

12 under microwave irradiation, the alkene fraction increased significantly, as well as the polycyclic

13 aromatic compounds.

14 Other studies relating to shale oil characterization by compound type, such as Wood et al. ${ }^{64}$,

15 make reference to an oil rich in paraffins and cycloparaffins, with carbon number extending to

$16 \mathrm{C}_{35}$. Also, Jones et al. ${ }^{65}$ compared shale and crude oil and found similar aromaticity for both

17 products. However, the oil obtained from decomposition of the oil shale under microwave

18 irradiation shows a highly aromatic character.

19 When comparing ion chromatograms for $\mathrm{m} / \mathrm{z} 57$, fragment ion characteristic of alkanes ${ }^{64}$, the

20 differences between the oils obtained under microwave or conventional heating are negligible, as

21 shown in Figure 13A. The intensity was normalized in Figure 13 due to the different dilution

22 degrees in both oils. However, when looking at the aromatic fraction (Figure 13B), defined for

$23 \mathrm{~m} / \mathrm{z}$ from 78 to 142 , the obtained pattern is different. For instance, the intensity in the ion 
1 chromatogram of the oil obtained under conventional heating is much lower, and therefore, the

2 noise increases. It is also possible to observe the presence of peaks at 4.7, 7.3 and $10.2 \mathrm{~min}$ in the

3 microwave heated sample which are not present in the conventional heating sample. These peaks

4 correspond, with a good match, to aromatic compounds such as styrene, indene and naphthalene,

5 respectively. As a result, the aromatic fraction in the oil from conventional heating is not as

6 important as for the shale oil obtained when microwave irradiation was used. This result is in

7 agreement with what was found regarding the amount of coke present in the spent shale samples

8 (Figure 6).

9 Total energy requirements. An important aspect to take into consideration when comparing

10 conventional and microwave heating is the energy consumption during both processes.

11 When the transformation of the oil shale was performed using conventional heating, an electric

12 oven was used, with automatic temperature control. The temperature increase is achieved via

13 pulses of electric current into the resistance heater. Figure 14 shows the power variation during

14 heating of the oil shale and compares it with the oven set point temperature. Integrating power as

15 a function of operating time, it is possible to calculate a rough estimate of the total energy

16 consumption for the operating conditions used. For the oil shale transformation under

17 conventional heating the energy consumed to heat the sample was about 506 Wh.

18 During microwave irradiation of the oil shale, the control unit would vary the magnetron

19 current according to the temperature requirements inside the microwave cavity. In this case, the

20 power output would be continuous as illustrated in Figure 15. Using these conditions, the energy

21 consumption was about $252 \mathrm{Wh}$ to heat the oil shale sample. Considering that the liquid products

22 yield was very similar for both cases, the energy consumption when using microwave irradiation

23 was about $50 \%$ of the energy consumed using conventional means. 
1 To maintain the dwell temperature at 300 or $500^{\circ} \mathrm{C}$, the electric oven needed about 600 to $21200 \mathrm{~W}$. Using microwave heating the power needed was of $400 \mathrm{~W}$. Additionally, tuning of the 3 microwave cavity decreased the power sent to the magnetron to about $100 \mathrm{~W}$ for the dwell at $4300^{\circ} \mathrm{C}$. Automatic tuning of the cavity during microwave heating could greatly improve energy 5 absorption by the sample and decrease the total energy consumption, making this point a key 6 factor for the process to be really advantageous, as far as energy requirements are concerned. 


\section{CONCLUSION}

2 The oil shale transformation in the presence of an acidic catalyst was achieved under flow

3 conditions and microwave radiation. The average temperature at which it occurs was found to be

4 lower than the one observed when heating by conventional means, related to the presence of

5 important temperature gradients within the oil shale bed. Insulation of the reactor to improve

6 temperature control inside the microwave cavity could help overcoming this problem.

7 Thermo-gravimetric analysis of the spent shale samples from microwave heating showed a

8 two-stage process, with a first step at $450-460^{\circ} \mathrm{C}$ and a second one at $720^{\circ} \mathrm{C}$, similar to what was

9 observed with the fresh oil shale sample. In contrast, after conventional heating of the oil shale,

10 the spent samples only presented the carbonate decomposition step, meaning that, under these

11 conditions, the organic matter was transformed to a greater extent than when using microwave

12 irradiation. Liquid products yield and composition were very similar for both microwave and

13 conventional heating. On the contrary, gas production was intensified in the latter case.

14 When adding water to the system under microwave heating, the average decomposition

15 temperature decreased. However, the products yield also decreased significantly. Shale oil

16 conversion was promoted by adding BEA zeolite to the oil shale sample. Under microwave

17 heating, a decrease in the average transformation temperature was detected, when comparing

18 with conventional heating. The total conversion of organic material was similar to the one

19 obtained for oil shale decomposition, performed without zeolite. However, coke production

20 increased at the expense of liquid products yield. Nevertheless, selectivity towards gas products

21 was improved, causing the yield for the " $<\mathrm{C}_{6}$ " fraction to increase, which is most likely due to

22 the intrinsic cracking activity associated with the zeolite. This effect was also observed under 
1 conventional heating, where the transformation temperature was similar with and without BEA

2 zeolite. Both " $<\mathrm{C}_{6}$ " and " $\mathrm{C}_{6}-\mathrm{C}_{10}$ " products selectivity increased in the presence of the zeolite.

3 Analysis of the oils obtained revealed an increase of the aromatic character of the products

4 obtained when using microwaves. This effect was clear when the zeolite was added to the system.

5 Adding zeolite and water to the system simultaneously, in a limited temperature range, could be a

6 solution to overcome increased coke formation due to the presence of the zeolite, since water

7 molecules could work as hydrogen supplier to the system, decreasing the formation of coke

8 precursors.

$9 \quad$ Finally, when comparing the energy consumed to heat the oil shale sample under microwave

10 and conventional heating, it was concluded that the use of microwaves is advantageous, given

11 that, for the same liquid products yield, the energy consumption is much lower. 


\section{AUTHOR INFORMATION}

\section{Corresponding Author}

*To whom correspondence should be addressed. Tel.: +351218419288 E-mail: carlos.henriques@ist.utl.pt

\section{ACKNOWLEDGMENTS}

The authors would like to thank the Centre Scientifique et Technique de Pau, TOTAL, for the oil shale samples supplied and Galp Energia for the simulated distillation analyses of the oil samples recovered. We are also grateful to Runjie Mao, Centre for Materials Science, University of Central Lancashire, Preston, for the technical support with the microwave setup which made this work possible.

A. Neto would like to thank the financial support from Fundação para a Ciência e Tecnologia (FCT) (ref. SFRH/BD/45051/2008). 


\section{REFERENCES}

(1) Conti, J. J.; Holtberg, P. D.; Annual Energy Outlook 2013, with projections to 2040. DOE/EIA-0383(2013); US Energy Information Administration: Washington, 2013.

(2) Motaghi, M.; Shree, K.; Krishnamurthy, S., Consider new methods for bottom of the barrel processing-Part 1. Hydrocarb. Process. 2010, 89, (2), 35-40.

(3) Rao, M. R.; Soni, D.; Sieli, G. M.; Bhattacharyya, D., Convert bottom-of-the-barrel into diesel and light olefins. Hydrocarb. Process. 2011, 90, (2), 45-49.

(4) Allen, R., et al.; A Technical, Economic and Legal Assessment of North American Heavy Oil, Oil Sands and Oil Shale Resources. Utah Heavy Oil Program, Institute for Clean and Secure Energy: The University of Utah, 2007.

(5) Johnson, H. R.; Crawford, P. M.; Bunger, J. W.; Strategic Significance of America's Oil Shale Resource, Volume I, Assessment of strategic issues. AOC Petroleum Support Services, US Department of Energy: Washington, 2004.

(6) Speight, J. G., The Chemistry and Technology of Petroleum. 3rd edition ed.; Marcel Dekker: New York, USA, 1999.

(7) Lankford, J. D.; Ellis, C. F., Shale Oil Refining. Ind. Eng. Chem. 1951, 43, (1), 27-32.

(8) Senguler, I.; Ayyildiz, T.; Onal, Y.; Onal, M., Organic geochemical characterization and mineralogic properties of mengen oil shale (Lutetian), Bolu-Turkey. Oil Shale 2008, 25, (3), 359375. 
(9) Aboulkas, A.; El Harfi, K., Study of the kinetics and mechanisms of thermal decomposition of moroccan tarfaya oil shale and its kerogen. Oil Shale 2008, 25, (4), 426-443.

(10) Lafargue, E.; Marquis, F.; Pillot, D., Rock-Eval 6 applications in hydrocarbon exploration, production, and soil contamination studies. Rev. I. Fr. Petrol. 1998, 53, (4), 421-437.

(11) Shell; Plan of Operations: Oil Shale Research and Development Project. Shell Frontier Oil and Gas Inc.: February 15, 2006.

(12) Vinegar, H. J., et al.; Systems, methods and processes for use in treating subsurface formations. WO2008131212, Oct. 30, 2008.

(13) Vinegar, H. J., et al.; Thermal Processes for Subsurface Formations. U.S. Patent 7,360,588 B2, Apr. 22, 2008.

(14) El Harfi, K.; Mokhlisse, A.; Chanaa, M. B.; Outzourhit, A., Pyrolysis of the Moroccan (Tarfaya) oil shales under microwave irradiation. Fuel 2000, 79, (7), 733-742.

(15) Mutyala, S., et al., Microwave applications to oil sands and petroleum: A review. Fuel Process. Technol. 2010, 91, (2), 127-135.

(16) Hascakir, B.; Akin, S., Recovery of Turkish Oil Shales by Electromagnetic Heating and Determination of the Dielectric Properties of Oil Shales by an Analytical Method. Energy Fuels 2010, 24, (1), 503-509.

(17) Shields, G., Raytheon Technology shows promise in extracting oil from shale. Microwave J. 2006, 49, (7), 285-288. 
(18) Bradhurst, D. H.; Worner, H. K., Evaluation of oil produced from the microwave retorting of Australian shales. Fuel 1996, 75, (3), 285-288.

(19) Butts, J. R.; Lewis, J. E.; Steward, F. R., Microwave-heating of New-Brunswick oil shale. J. Microwave. Power E. E. 1983, 18, (1), 37-43.

(20) Dumbaugh, W. H., Jr.; Lawless, W. N.; Malmendier, J. W.; Wexel, D. R.; Extraction of oil from oil shale and tar sands. Canadian Patent 1,108,081, Sep. 1, 1981.

(21) Balint, V.; Pinter, A.; Mika, G.; Process for the recovery of shale oil, heavy oil, kerogen or tar from their natural sources. U.S. Patent 4,419,214, Dec. 6, 1983.

(22) Kinzer, D. E.; In situ processing of hydrocarbon-bearing formations with variable frequency automated capacitive radio frequency dielectric heating. U.S. Patent 7,091,460 B2, Aug. 15, 2006.

(23) Kearl, P. M.; Ensley, D. L.; Microwave process for intrinsic permeability enhancement and hydrocarbon extraction from subsurface deposits. U.S. Patent 2008/0265654 A1, Oct. 30, 2008.

(24) Worner, H. K.; Burton, P.; Pyrolysis of oil containing shale using microwave irradiation. AU-B-32534/89, June 11, 1989.

(25) Varma, R.; High power microwave petroleum recovery and refinement. WO 2009/085347 A1, Sep. 23, 2008.

(26) Sresty, G. C.; Snow, R. H.; Bridges, J. E.; Recovery of liquid hydrocarbons from oil shale by electromagnetic heating in situ. Canadian Patent No. 1213547, Nov. 4, 1986. 
(27) Cogliandro, J. A.; Moses, J. M.; Method and apparatus for capture and sequester of carbon dioxide and extraction of energy from large land masses during and after extraction of hydrocarbon fuels or contaminants using energy and critical fluids. U.S. Patent 2007/0261844 A1, Nov. 15, 2007.

(28) Kasevich, R. S.; Koleker, M.; Dwyer, A. S.; In situ radio frequency selective heating process. U.S. Patent 4,140,179, Feb. 20, 1979.

(29) Judzis, A., Jr.; Hiatt, R. E.; Williams, B.; Judzis, A., Absorption of microwave-energy by oil-shale - Effects of shale richness, packing factor, and frequency. Ind. Eng. Chem. Process Des. Dev. 1980, 19, (3), 465-469.

(30) Meredith, R., Engineers' Handbook of Industrial Microwave Heating. The Institution of Electrical Engineers: London, 1998; p 363.

(31) Durka, T.; Van Gerven, T.; Stankiewicz, A., Microwaves in Heterogeneous Gas-Phase Catalysis: Experimental and Numerical Approaches. Chem. Eng. Technol. 2009, 32, (9), 13011312.

(32) Roland, U.; Kopinke, F. D., The Role of Water in Dielectric Heating with Radio Waves. Chem. Eng. Technol. 2009, 32, (5), 754-762.

(33) Hakala, J. A.; Stanchina, W.; Soong, Y.; Hedges, S., Influence of frequency, grade, moisture and temperature on Green River oil shale dielectric properties and electromagnetic heating processes. Fuel Process. Technol. 2011, 92, (1), 1-12. 
(34) Al-Harahsheh, M., et al., Dielectric properties of Jordanian oil shales. Fuel Process. Technol. 2009, 90, (10), 1259-1264.

(35) Na, J. G.; Im, C. H.; Chung, S. H.; Lee, K. B., Effect of oil shale retorting temperature on shale oil yield and properties. Fuel 2012, 95, (0), 131-135.

(36) Cheng, W.-C., et al., Fluid Catalytic Cracking. In Handbook of Heterogeneous Catalysis, Wiley-VCH Verlag GmbH \& Co. KGaA: 2008; Vol. 1, pp 2741-2778.

(37) Gorring, R. L.; Smith, R. L.; Upgrading Shale Oil. U.S. Patent 4,153,540, May 8, 1979.

(38) Williams, P. T.; Chishti, H. M., Two stage pyrolysis of oil shale using a zeolite catalyst. $J$. Anal. Appl. Pyrolysis 2000, 55, (2), 217-234.

(39) Guisnet, M.; Cerqueira, H. S.; Figueiredo, J. L.; Ribeiro, F. M. R. C., Desactivação e regeneração de catalisadores. Fundação Calouste Gulbenkian: Lisboa, 2008.

(40) Kustov, L. M.; Sinev, I. M., Microwave Activation of Catalysts and Catalytic Processes. Russ. J. Phys. Chem. A 2010, 84, (10), 1676-1694.

(41) Sykes, R.; Snowdon, L. R., Guidelines for assessing the petroleum potential of coaly source rocks using Rock-Eval pyrolysis. Org. Geochem. 2002, 33, (12), 1441-1455.

(42) Peters, K. E.; Cassa, M. R., Applied Source Rock Geochemistry. In The Petroleum System - From Source to Trap (AAPG Memoirs), Magoon, L. B.; Dow, W. G., Eds. American Association of Petroleum Geologists: 1994; Vol. 60, pp 93 - 120. 
(43) Peters, K. E., Guidelines for evaluating petroleum source rock using programmed pyrolysis. AAPG Bull. 1986, 70, (3), Medium: X; Size: Pages: 318-329.

(44) Johannes, I.; Kruusement, K.; Veski, R., Evaluation of oil potential and pyrolysis kinetics of renewable fuel and shale samples by Rock-Eval analyzer. J. Anal. Appl. Pyrolysis 2007, 79, (1-2), 183-190.

(45) Parkes, G. M. B.; Bond, G.; Barnes, P. A.; Charsley, E. L., Development of a new instrument for performing microwave thermal analysis. Rev. Sci. Instrum. 2000, 71, (1), 168-175.

(46) Bond, G.; Moyes, R. B.; Whan, D. A., RECENT APPLICATIONS OF MICROWAVEHEATING IN CATALYSIS. Catalysis Today 1993, 17, (3), 427-437.

(47) Zhang, X. L.; Hayward, D. O.; Mingos, D. M. P., Effects of microwave dielectric heating on heterogeneous catalysis. Catalysis Letters 2003, 88, (1-2), 33-38.

(48) Thomas, J. R., Particle size effect in microwave-enhanced catalysis. Catalysis Letters 1997, 49, (3-4), 137-141.

(49) Williams, P. T.; Ahmad, N., Investigation of oil-shale pyrolysis processing conditions using thermogravimetric analysis. Appl. Energ. 2000, 66, (2), 113-133.

(50) Jaber, J. O.; Probert, S. D., Non-isothermal thermogravimetry and decomposition kinetics of two Jordanian oil shales under different processing conditions. Fuel Process. Technol. 2000, 63, (1), 57-70.

(51) Silverstein, R. M.; Bassler, G. C.; Cauquis, G., Identification spectrométrique des composés organiques. Masson et Cie Gauthier-Villars: Paris, 1968. 
(52) Feist, P.; Molecular Vibrations - 15 "Infrared Spectroscopy: Theory", 2002. Department of Chemistry and Biochemistry, University of Colorado at Boulder. Available online http://orgchem.colorado.edu/Spectroscopy/irtutor/IRtheory.pdf (accessed November 27, 2013).

(53) La Spectroscopie Infrarouge à Transformée de Fourier, 2012. Biophy Research. Available online $\quad$ http://www.biophyresearch.com/technique-analyse/la-spectroscopie-infrarouge-atransformee-de-fourier/ (accessed November 27, 2013).

(54) Harrison, G. R.; Lord, R. C.; Loofbourow, J. R., Practical spectroscopy. Prentice-Hall: Englewood Cliffs, 1948.

(55) Kemp, W., Organic spectroscopy. Third ed.; Macmillan: Houndmills, 1991.

(56) Acetone: Infrared Spectrum, National Institute of Standards and Technology. Available online $\quad$ http://webbook.nist.gov/cgi/cbook.cgi?ID=C67641\&Units=SI\&Type=IR-

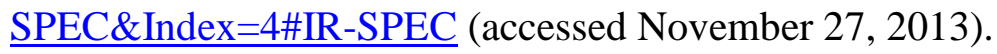

(57) Muller, A. L. H., et al., Total sulfur determination in residues of crude oil distillation using FT-IR/ATR and variable selection methods. Spectrochim. Acta, Part A 2012, 89, (0), 8287.

(58) Subramanian, M.; Deo, M. D.; Hanson, F. V., Compositional Analysis of Bitumen and Bitumen-Derived Products. J. Chromatogr. Sci. 1996, 34, (1), 20-26.

(59) Higher-Temperature Simulated Distillation with DB-HT Sim Dis Columns - Application, 2002. Agilent Technologies. Available online http://www.chem.agilent.com/Library/applications/5988-7929EN.pdf (accessed June 2013). 
(60) Yoon, S.; Choi, W.; Park, Y.-K.; Kim, H.; Lee, C., Catalytic hydrocracking of bitumen at mild experimental condition. Korean J. Chem. Eng. 2010, 27, (1), 62-65.

(61) Glover, C. J.; Bullin, J. A., Identification of heavy residual oils by GC and GC-MS. J. Environ. Sci. Health, Part A 1989, 24, (1), 57-75.

(62) McFadden, W. H., Techniques of combined gas chromatography / mass spectrometry: applications in organic analysis. Wiley-Interscience: New York, 1973.

(63) Morandi, J. R.; Guffey, F., Identification of isoprenoids, steranes, and terpanes in Fischer Assay retorted shale oils. Abstr. Pap. Am. Chem. Soc. 1978, 175, (MAR), 27-27.

(64) Wood, K. V.; Narayan, R.; Stringham, K. R.; Huang, S. L.; Leehe, H., Characterization of the oil extract of an indiana shale. Fuel Process. Technol. 1990, 26, (2), 73-81.

(65) Jones, P. W.; Graffeo, A. P.; Strup, P. E., Chemical characterization of shale oil and related fuels. Abstr. Pap. Am. Chem. Soc. 1976, 172, (SEP3), 75. 


\section{LIST OF TABLES}

Table 1. Elemental weight composition of the oil obtained using microwave heating to decompose the oil shale; comparison with conventional crude oil.

\begin{tabular}{ccc}
\hline \multirow{2}{*}{ Element } & $\begin{array}{c}\text { Shale oil from microwave heating, } \\
\text { wt.\% }\end{array}$ & $\begin{array}{c}\text { Conventional Petroleum } \\
\text { wt.\% }\end{array}$ \\
\hline $\mathrm{C}$ & $86.5 \pm 0.2$ & $83.0-87.0$ \\
$\mathrm{H}$ & $10.0 \pm 0.2$ & $10.0-14.0$ \\
$\mathrm{~N}$ & $1.30 \pm 0.01$ & $0.1-2.0$ \\
$\mathrm{~S}$ & $<2$ & $0.05-6.0$ \\
\hline
\end{tabular}

Table 2. Elemental analysis results of fresh and spent shale samples.

\begin{tabular}{ccccc}
\hline & & \multicolumn{3}{c}{ Spent shale samples } \\
\cline { 3 - 5 } Content, wt. \% & Fresh oil shale & mw & mw \& water & $\begin{array}{c}\text { Conventional } \\
\text { heating }\end{array}$ \\
\hline $\mathrm{C}$ & 42.42 & 26.31 & 35.42 & 18.85 \\
$\mathrm{H}$ & 4.75 & $<2$ & 3.28 & $<2$ \\
$\mathrm{~N}$ & 0.70 & 0.51 & 0.66 & 0.51 \\
$\mathrm{~S}$ & $<2$ & $<2$ & $<2$ & $<2$ \\
\hline $\mathrm{H} / \mathrm{C}$ (mol ratio) & 1.3 & 0.9 & 1.1 & 1.3 \\
\hline
\end{tabular}


Table 3. Transformation temperatures obtained for oil shale decomposition under microwave irradiation; organic matter balance for each experiment.

\begin{tabular}{|c|c|c|c|c|c|}
\hline Experiment & $\begin{array}{c}\text { Transformation } \\
\text { temperature } \\
\text { (start) } \\
{ }^{\circ} \mathrm{C}\end{array}$ & $\begin{array}{c}\text { Initial } \\
\text { organic } \\
\text { content }^{a} \\
\text { wt. } \%\end{array}$ & $\begin{array}{l}\text { Liquid } \\
\text { products } \\
\text { yield } \\
\text { wt.\% }\end{array}$ & $\begin{array}{c}\text { Organics not } \\
\text { recovered } \\
\text { wt. } \%\end{array}$ & $\begin{array}{c}\text { Gas produced } \\
\text { wt. } \%\end{array}$ \\
\hline \multicolumn{6}{|c|}{ Microwave heating } \\
\hline $\begin{array}{l}\text { Oil shale } \\
\text { transformation }\end{array}$ & 300 & 47 & 49 & 34 & 18 \\
\hline $\begin{array}{l}\text { Addition of } \\
5 \text { wt.\% BEA }\end{array}$ & 245 & 45 & 30 & 49 & 21 \\
\hline $\begin{array}{l}\text { Presence of water } \\
\text { vapour }\end{array}$ & 242 & 47 & 32 & 55 & 12 \\
\hline \multicolumn{6}{|c|}{ Conventional heating } \\
\hline $\begin{array}{l}\text { Oil shale } \\
\text { transformation }\end{array}$ & 380 & 47 & 51 & 18 & 31 \\
\hline $\begin{array}{l}\text { Addition of } \\
5 \text { wt.\% BEA }\end{array}$ & 380 & 45 & 52 & 16 & 32 \\
\hline
\end{tabular}

${ }^{a}$ from TGA.

Table 4. Total conversion and selectivity by product fraction, using microwave irradiation and conventional heating.

\begin{tabular}{l|c|cccc}
\hline Experiment & $\begin{array}{c}\text { Total Conversion } \\
\text { Microwave heating }\end{array}$ & $<\mathrm{C}_{6}$ & $\mathrm{C}_{6}-\mathrm{C}_{10}$ & $\mathrm{C}_{10}-\mathrm{C}_{16}$ & $\mathrm{C}_{16}$ \\
\hline \multicolumn{1}{c|}{ M } & 70 & 36 & 28 & 23 & 8 \\
\hline $\begin{array}{l}\text { Oil shale } \\
\text { transformation } \\
\begin{array}{l}\text { Addition of } \\
5 \text { wt.\% BEA }\end{array}\end{array}$ & 70 & 44 & 16 & 9 & 2 \\
$\begin{array}{l}\text { Presence of water } \\
\text { vapour }\end{array}$ & 49 & 43 & 26 & 18 & 5 \\
\hline \multicolumn{1}{c}{ Conventional heating } & 84 & 45 & 26 & 21 & 6 \\
\hline $\begin{array}{l}\text { Oil shale } \\
\text { transformation }\end{array}$ & 85 & 47 & 30 & 16 & 6 \\
$\begin{array}{l}\text { Addition of } \\
5 \text { wt.\% BEA }\end{array}$ & 84 & & & \\
\hline
\end{tabular}


Table 5. Identification of the bands observed in the regions $3500-2400 \mathrm{~cm}^{-1}$ and $2000-700 \mathrm{~cm}^{-1}$.

\begin{tabular}{lllc}
\hline & \multicolumn{1}{c}{ Vibration type } & & Wavenumber, $\mathrm{cm}^{-1}$ \\
\hline & Asymmetric stretching & $v_{\mathrm{as}}\left(\mathrm{CH}_{3}\right)$ & 2960 \\
\multirow{4}{*}{ Methyl groups } & Symmetric stretching & $v_{\mathrm{s}}\left(\mathrm{CH}_{3}\right):$ & 2872 \\
& Asymmetric bending & $\delta_{\mathrm{as}}\left(\mathrm{CH}_{3}\right)$ & 1454 \\
& Symmetric bending & $\delta_{\mathrm{s}}\left(\mathrm{CH}_{3}\right)$ & 1377 \\
\hline \multirow{3}{*}{ Methylene bridge } & Asymmetric stretching & $v_{\mathrm{as}}\left(\mathrm{CH}_{2}\right)$ & 2921 \\
& Symmetric stretching & $v_{\mathrm{s}}\left(\mathrm{CH}_{2}\right)$ & 2852 \\
& Scissoring & $\delta_{\mathrm{s}}\left(\mathrm{CH}_{2}\right)$ & 1460 \\
\hline
\end{tabular}




\section{LIST OF FIGURES}

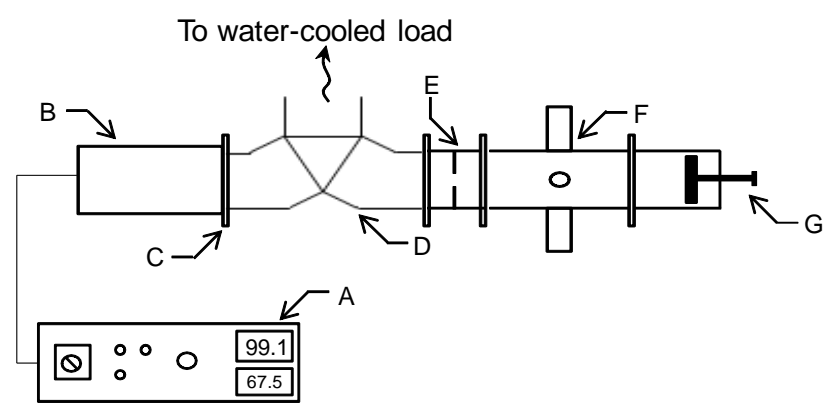

Figure 1. Schematic diagram of the microwave setup used in the study. (A) Variable power generator, (B) magnetron, (C) waveguide flange connector, (D) water-cooled circulator, (E) variable coupling aperture, (F) sample section, (G) plunge tuner.

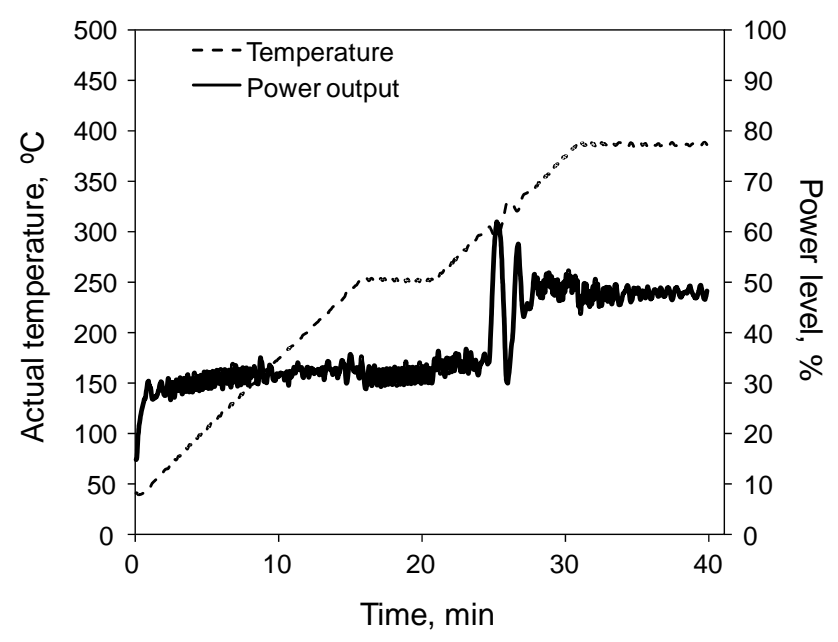

Figure 2. Data obtained from the power output control system of the microwave generator for a given temperature program. 


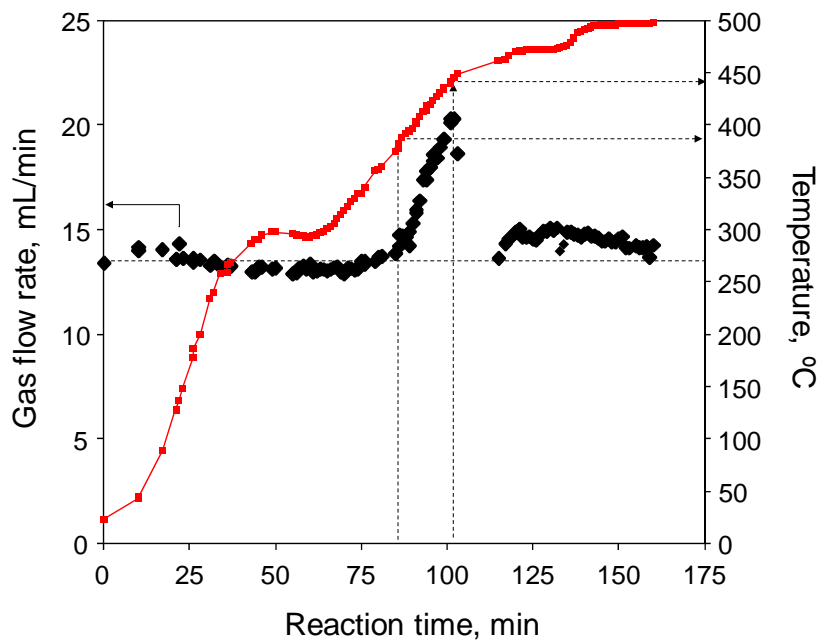

Figure 3. Gas flow rate measurement $(\diamond)$ during oil shale transformation under conventional heating; relation with sample’s temperature ( $\square$ ). 
A

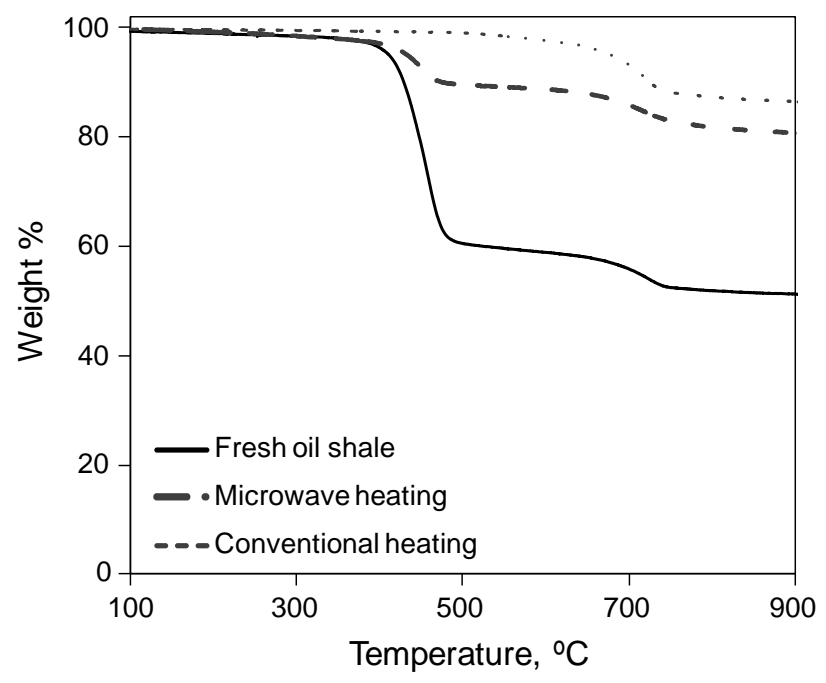

B

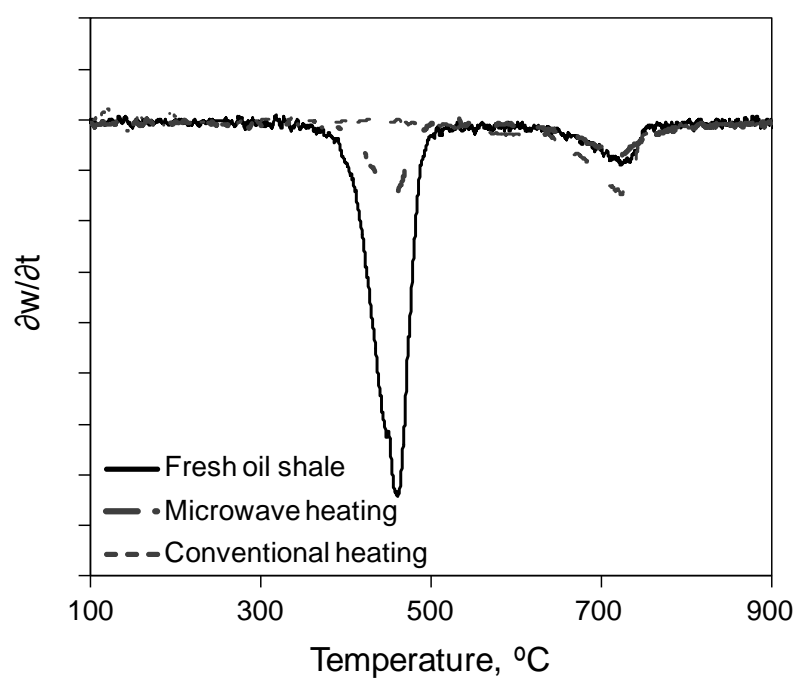

Figure 4. TGA of fresh and spent shale samples from decomposition under microwave irradiation and conventional heating, experiments under nitrogen flow (A); weight derivative in function of time (B). 


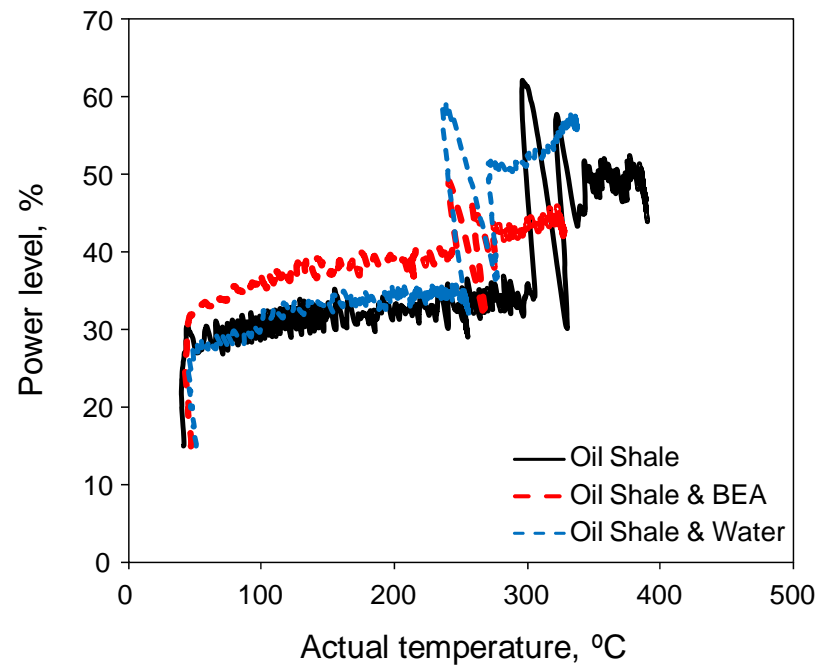

Figure 5. Power level from the microwave generator control system reported to the sample temperature; comparison between all experiments using microwave heating.

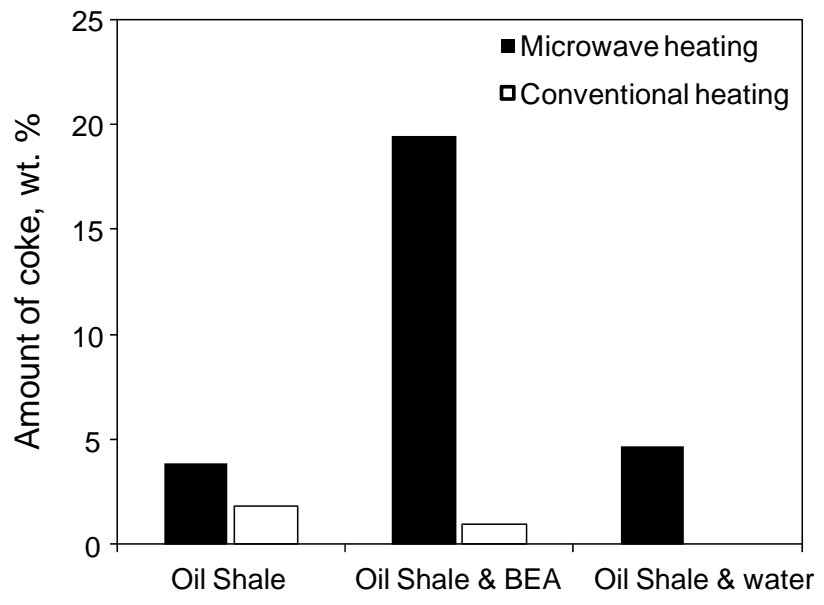

Figure 6. Comparison of the amount of coke produced for the experiments using microwave and conventional heating. 
A

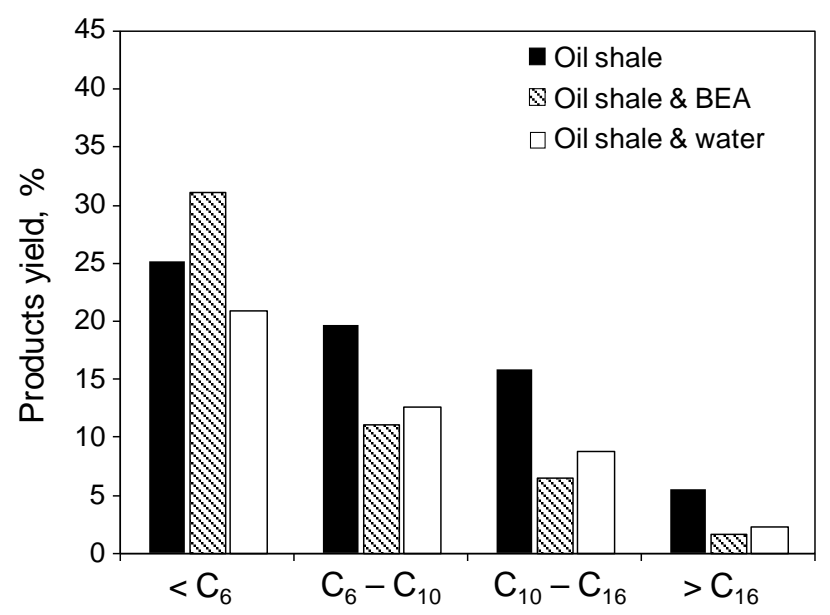

B

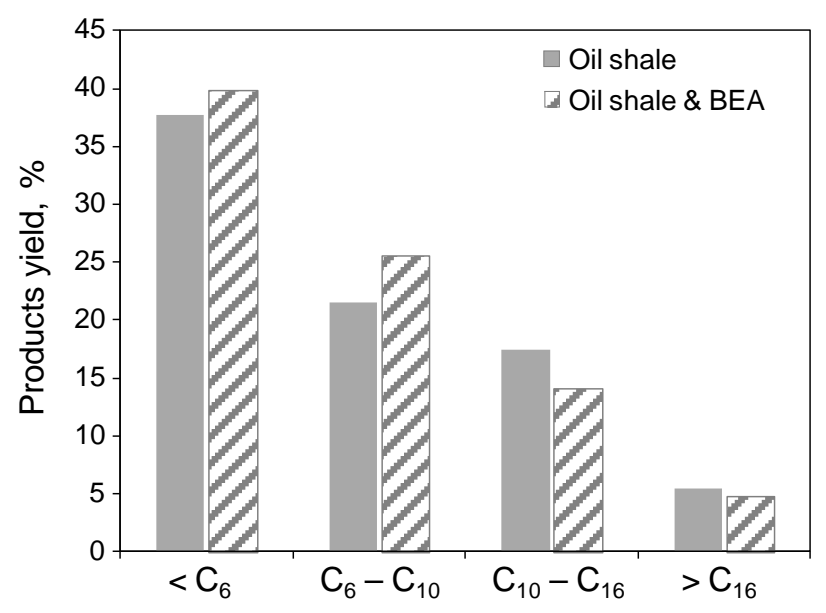

Figure 7. Products yield for the cases studied under microwave irradiation (A) and conventional heating (B). 
A

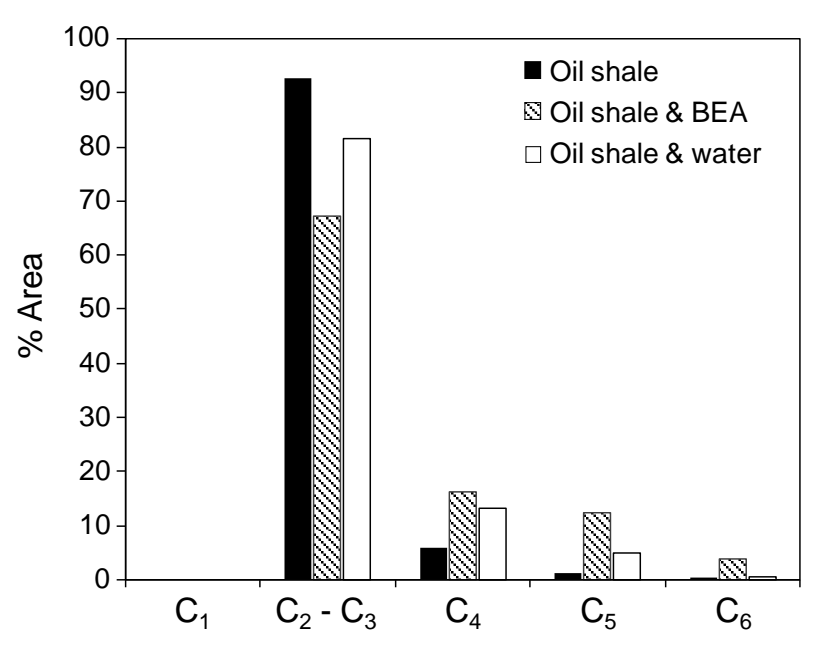

B

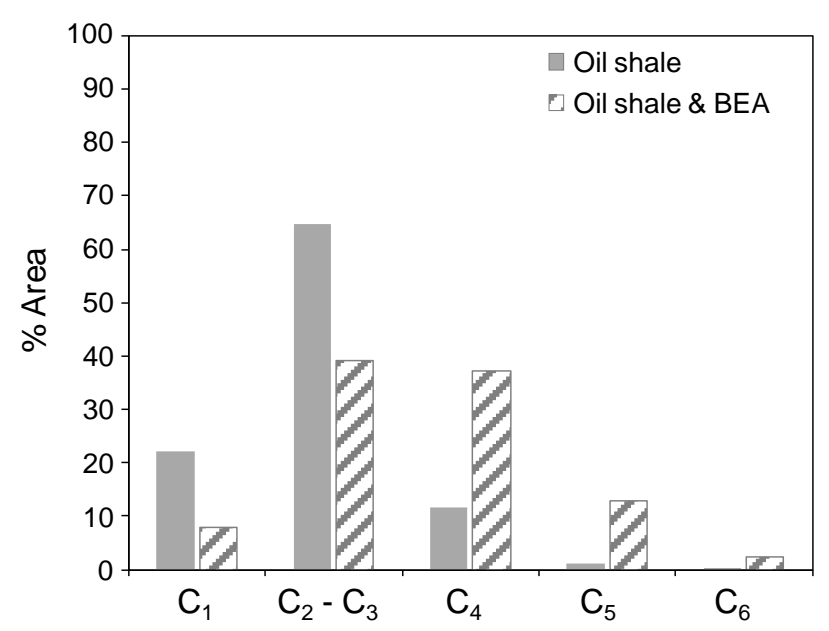

Figure 8.Result from peak integration of the GC-MS chromatogram for the gas samples obtained via microwave irradiation (A); peak integration of the chromatogram from GC of the gas samples obtained via conventional heating (B). 


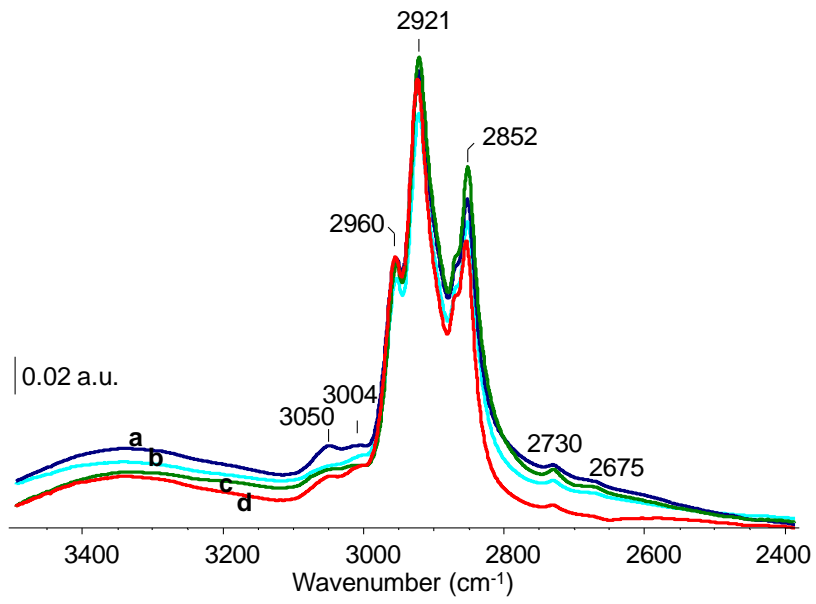

Figure 9. Normalized IR spectra in the $v(\mathrm{C}-\mathrm{H})$ vibration region: a - microwave heating; $\mathrm{b}$ conventional heating with BEA zeolite; c - conventional heating; d - microwave heating with BEA zeolite.

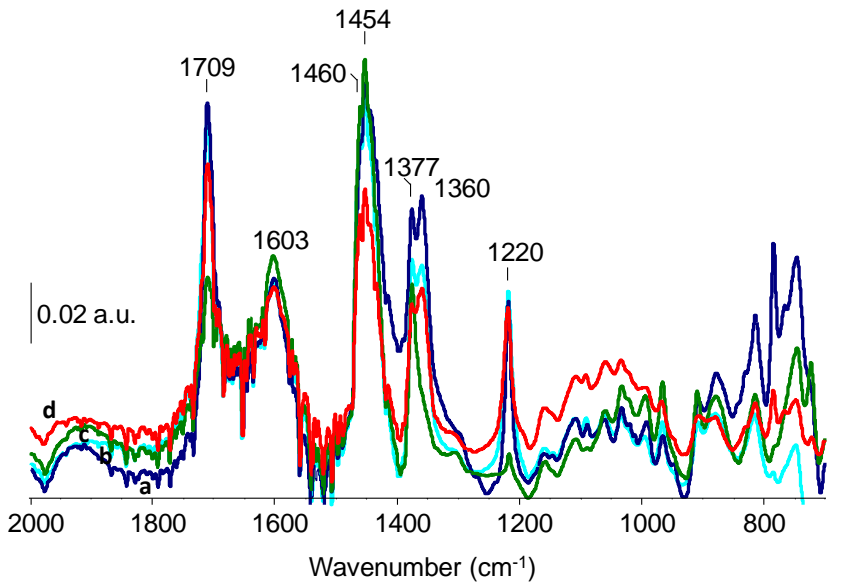

Figure 10. Normalized IR spectra in the $\delta(\mathrm{C}-\mathrm{H})$ vibration region: a - microwave heating; b conventional heating with BEA zeolite; c - conventional heating; $d$ - microwave heating with BEA zeolite. 
A

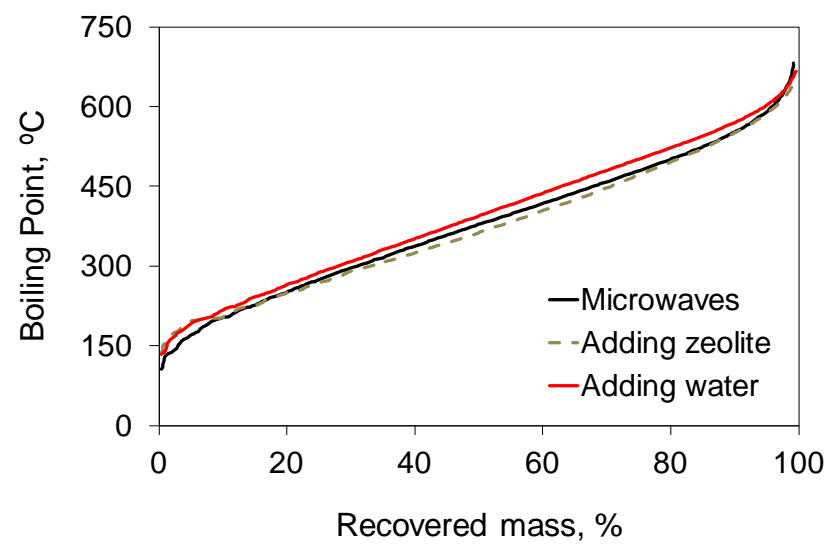

B

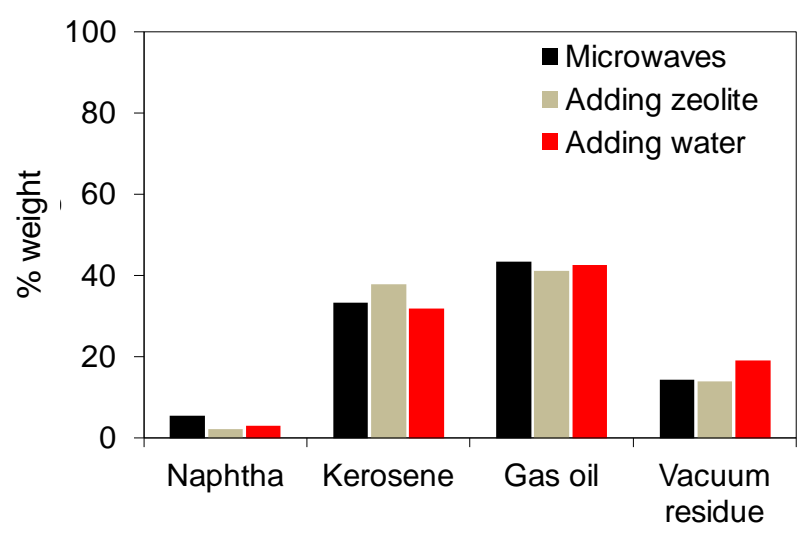

Figure 11. For all the liquids obtained using microwave heating, simulated distillation curves (A) and percent mass recovered per boiling point cut (B). 


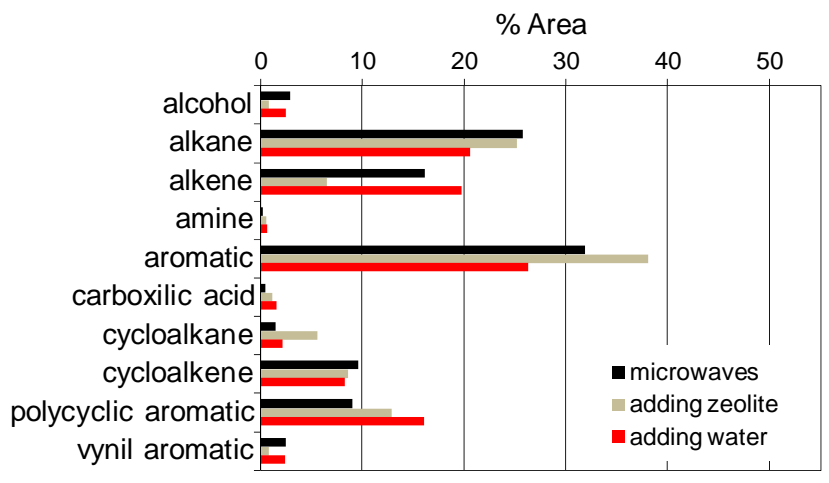

Figure 12. Percent area obtained for each group of organic compounds found in the liquids obtained in the experiments using microwave irradiation. 


\section{A}

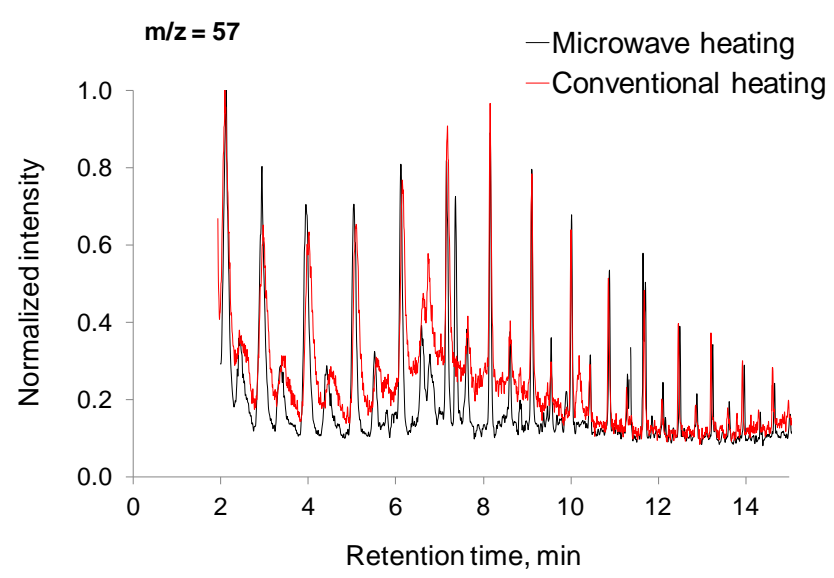

B

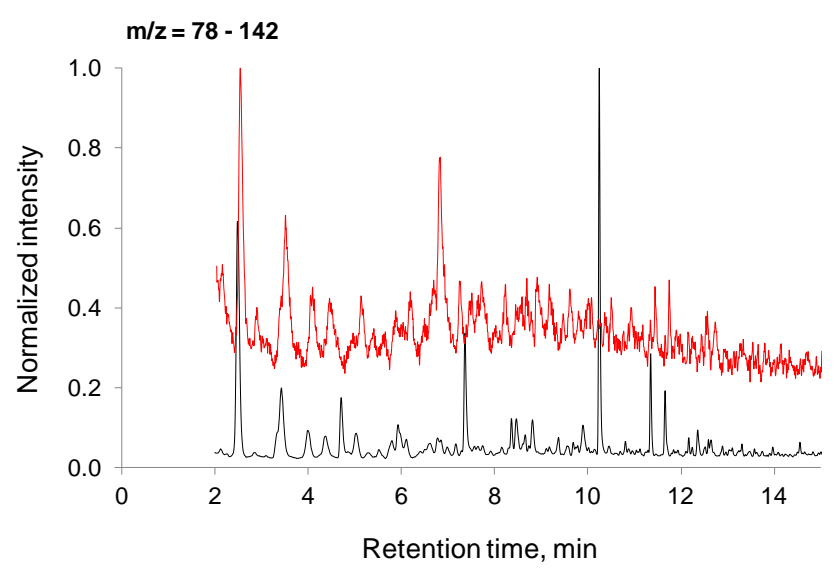

Figure 13. Normalized ion chromatograms for (A) $\mathrm{m} / \mathrm{z}$ of 57 and (B) $\mathrm{m} / \mathrm{z}$ of 78 to 142, with respect to the oils obtained under microwave and conventional heating. 


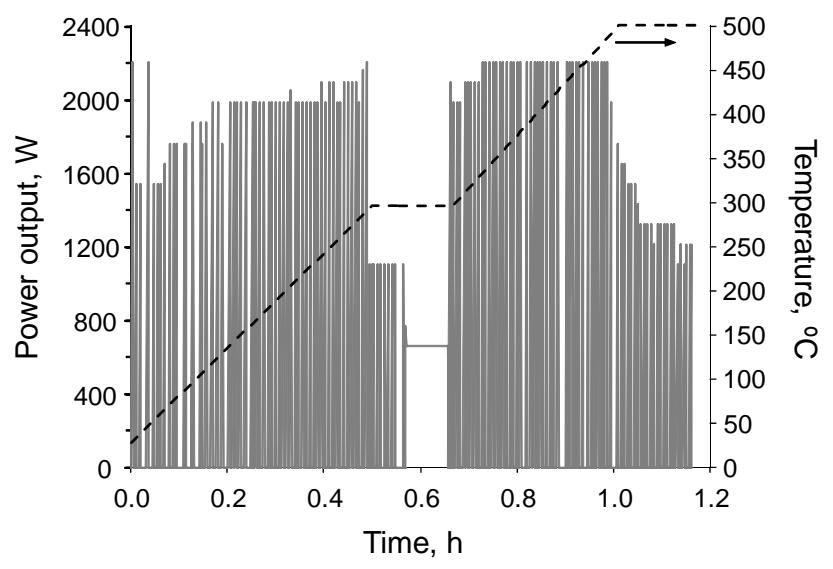

Figure 14. Power variation (-) during operation of the oven for oil shale transformation and relation with the oven temperature set point $(---)$.

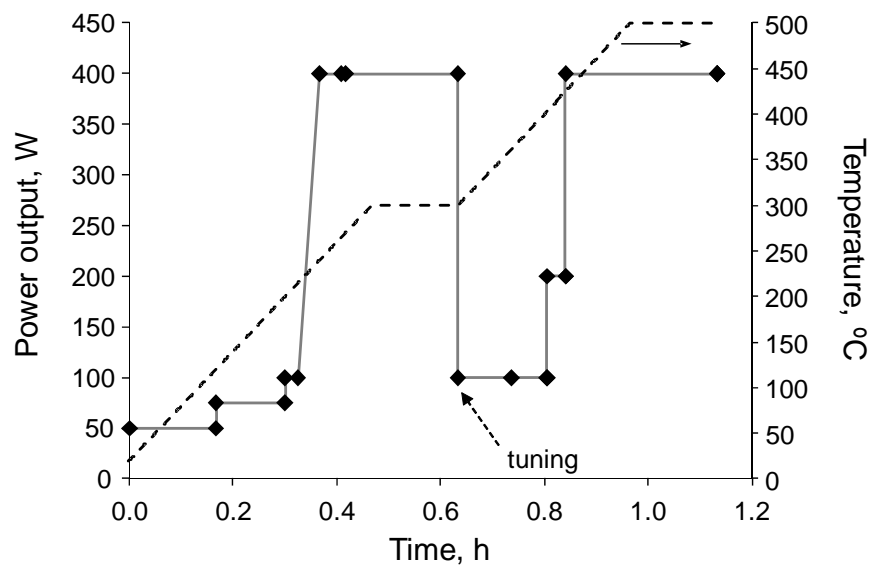

Figure 15. Power output during microwave irradiation of the oil shale sample (»); comparison with temperature set point (-- ). 